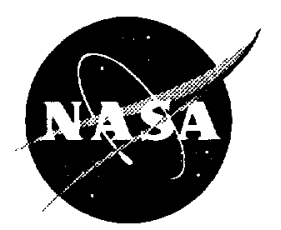

\title{
Development of an Ion Thruster and Power Processor for New Millennium's Deep Space 1 Mission
}

James S. Sovey, John A. Hamley, Thomas W. Haag, Michael J. Patterson, Eric J. Pencil, Todd T. Peterson, Luis R. Pinero, John L. Power, Vincent K. Rawlin, and Charles J. Sarmiento NASA Lewis Research Center, Cleveland, Ohio

John R. Anderson, Raymond A. Becker, John R. Brophy, and James E. Polk Jet Propulsion Laboratory, Pasadena, California

Gerald Benson, Thomas A. Bond, G. I. Cardwell, Jon A. Christensen, Kenneth J. Freick, David J. Hamel, Stephen L. Hart, John McDowell, Kirk A. Norenberg, T. Keith Phelps, Ezequiel Solis, and Harold Yost

Hughes Electron Dynamics Division, Torrance, California

Michael Matranga

Spectrum Astro Incorporated, Gilbert, Arizona

Prepared for the 33rd Joint Propulsion Conference and Exhibit cosponsored by AIAA, ASME, SAE, and ASEE

Seattle, Washington, July 6-9, 1997

National Aeronautics and Space Administration

Lewis Research Center 
This report contains preliminary findings, subject to revision as analysis proceeds.

Available from

NASA Center for Aerospace Information 800 Elkridge Landing Road

Linthicum Heights, MD 21090-2934

Price Code: A03
National Technical Information Service 5287 Port Royal Road Springfield, VA 22100

Price Code: A03 


\section{DEVELOPMENT OF AN ION THRUSTER AND POWER PROCESSOR FOR NEW MILLENNIUM'S DEEP SPACE 1 MISSION}

James S. Sovey, John A. Hamley, Thomas W. Haag, Michael J Patterson, Eric J. Pencil, Todd T. Peterson, Luis R. Pinero, John L. Power, Vincent K. Rawlin, and Charles J. Sarmiento

NASA Lewis Research Center

Cleveland, Ohio

and

John R. Anderson, Raymond A. Becker, John R. Brophy, and James E. Polk

Jet Propulsion Laboratory

Pasadena, California

and

Gerald Benson, Thomas A. Bond, G. I. Cardwell, Jon A. Christensen, Kenneth J. Freick,

David J. Hamel, Stephen L. Hart, John McDowell, Kirk A. Norenberg, T. Keith Phelps,

Ezequiel Solis, and Harold Yost

Hughes Electron Dynamics Division

Torrance, California

and

Michael Matranga

Spectrum Astro Incorporated

Gilbert, Arizona

$\underline{\text { Abstract }}$

The NASA Solar Electric Propulsion Technology Applications Readiness Program (NSTAR) will provide a single-string primary propulsion system to NASA's New Millennium Deep Space 1 Mission which will perform comet and asteroid flybys in the years 1999 and 2000 . The propulsion system includes a $30-\mathrm{cm}$ diameter ion thruster, a xenon feed system, a power processing unit, and a digital control and interface unit. A total of four engineering model ion thrusters, three breadboard power processors, and a controller have been built, integrated, and tested. An extensive set of development tests has been completed along with thruster design verification tests of $2000 \mathrm{~h}$ and $1000 \mathrm{~h}$. An $8000 \mathrm{~h}$ Life Demonstration Test is ongoing and has successfully demonstrated more than $6000 \mathrm{~h}$ of operation. In situ measurements of accelerator grid wear are consistent with grid lifetimes well in excess of the $12,000 \mathrm{~h}$ qualification test requirement. Flight hardware is now being assembled in preparation for integration, functional, and acceptance tests.

\section{Nomenclature}

BOL Beginning-of-Life

BBPPU Breadboard Power Processing Unit
CMOS Complementary Metal Oxide Semiconductor

CSVS Component and Spacecraft Verification Specification (for Deep Space 1)

DCIU Digital Control and Interface Unit

DS1 Deep Space 1

EMDCIU Engineering Model Digital Control and Interface Unit

EMI Electromagnetic Interference

EMT Engineering Model Thruster

FT Flight Thruster

GN\&C Guidance Navigation and Control

HBBPPU Hughes Breadboard Power Processing Unit

HEDD Hughes Electron Dynamics Division of the Hughes Telecommunications and Space Company

I\&T Integration and Test

JPL Jet Propulsion Laboratory

LeRC Lewis Research Center

LDT Life Demonstration Test

NASA National Aeronautics and Space Administration

NSTAR NASA Solar Electric Propulsion Technology Applications Readiness

PAT Performance Acceptance Test

PPU Power Processing Unit

PWM Pulse-Width Modulated

S/C Spacecraft

TTT Thruster Throttling Test

VF5 Vacuum Facility 5 (at LeRC)

VME Versa Module Eurocard 


\begin{tabular}{cl} 
XEM & $\begin{array}{l}\text { Engineering Model Xenon Feed } \\
\text { System } \\
\text { Xenon Feed System }\end{array}$ \\
\multicolumn{1}{c}{ Introduction }
\end{tabular}

Xenon ion propulsion systems are attractive candidates for use on planetary and Earthorbital spacecraft, and development of these systems has been ongoing in the United States and abroad over the last ten years. NASA's focus has been on kilowatt-class ion propulsion systems which can deliver more spacecraft payload to comets and asteroids in a shorter period of time than chemical propulsion systems ${ }^{1}$. Ion propulsion systems are appropriate for a large range of exploration missions because they make the spacecraft less massive and less expensive. Near-term development of 2 to $3 \mathrm{~kW}$ class power processor/thruster subsystems will provide modular elements to respond to mission total impulse and reliability requirements.

The NSTAR Project was organized to validate ion propulsion technology for a wide class of planetary missions including flybys, rendezvous, and sample/returns. The objective of the project is to obtain sufficient information needed to allow a Project Manager to baseline solar electric propulsion on a spacecraft and also develop industrial sources for the ion propulsion technology. The NSTAR project will use ground testing to validate lifetime and performance, and in-space operation will measure interactions between the ion propulsion system and the spacecraft. NSTAR will provide a single-string ion propulsion system to New Millennium's Deep Space 1 Mission which will perform comet and asteroid flybys in the years 1999 and $2000^{2}$. Preliminary targets are the asteroid $3352 \mathrm{McAuliffe}$ and comet $76 \mathrm{P} / \mathrm{West}-$ Kohoutek-Ikemura. Launch is scheduled for July 1998. The ion propulsion system will be powered from a solar concentrator array which has $2.6 \mathrm{~kW}$ at beginning-of-life. The propulsion system includes a $30-\mathrm{cm}$ diameter ion thruster, a xenon feed system, a power processing unit, and a digital control and interface unit. Continuous throttling of the ion thruster is possible over a $0.5 \mathrm{~kW}$ to $2.3 \mathrm{~kW}$ range. At full-power, the total propellant flow rate is $2.9 \mathrm{mg} / \mathrm{s}$, the thrust is $92 \mathrm{mN}$, and the specific impulse is about $3300 \mathrm{~s}$. Deep Space 1 will validate the ion propulsion technology for use on the next century's demanding planetary science missions.

The NSTAR Project inherited a significant amount of expertise, thruster technology, power processor integration technology, and wear-test experience from previous NASA research and technology programs. Hollow cathode electrodes, ion optics, and propellant electrical isolator designs were derived from the Solar Electric Propulsion System Demonstration Proj$\mathrm{ect}^{3}$ and subsequent work under NASA's Research and Technology Program. NSTAR discharge chamber design and wear-test experiences with xenon ion thrusters were obtained from technology programs at NASA Lewis Research Center ${ }^{4}$, the Jet Propulsion Laboratory ${ }^{5}$, and the Hughes Telecommunications and Space Company ${ }^{6}$. Hollow cathode handling, test, and storage procedures were obtained directly from methods reported by NASA's Space Station Plasma Contactor Program? ${ }^{7}$ This component technology base was the foundation for the design and development of $\mathrm{kW}$-class engineering model xenon ion thrusters, breadboard PPUs, and finally flight hardware.

This paper will describe the NSTAR Thruster/Power Processor Element ground and in-space program. Results of engineering model development tests, environmental, and weartests are synopsized. The flight hardware requirements and the basic designs of the thruster, PPU, and the DCIU are described along with design drivers related to spacecraft integration and space environment.

\section{The NSTAR Project}

The NSTAR Project is comprised of six elements as shown in Figure 1: Mission Design/Requirements, Thruster/Power Processor, Feed System, Diagnostics, Integration, and User Validation Assessment. The focus of this paper is on the Thruster/Power Processor Element. Figure 2 shows a breakout of major elements of the NSTAR ground and in-space portions of the program.

NASA's research and technology programs in the 1988 to 1993 period lead to the development of mature laboratory-class, $30 \mathrm{~cm}$ diameter, xenon ion thrusters ${ }^{4}$. The NSTAR ground test program advanced the thruster design to engineering model level where the thruster weight was reduced in a flight-like design. Four EMTs were built and were dedicated to PPU integration, development, and wear-tests to demonstrate the performance and service life needed for a variety of demanding missions. NASA built two breadboard PPUs and HEDD built one, all of which were designed to operate over a wide range of bus voltages and produce a 4.6:1 power throttling capability while providing 
a specific mass of less than $5 \mathrm{~kg} / \mathrm{kW}$ and an efficiency in excess of 0.92 at full-power. One of the important ground test program goals was to demonstrate successful integration of the DCIU, BBPPU, and the EMT. The design of the thruster and BBPPUs was validated through a series of development and wear-tests. A subset of these tests is identified in Table 1. Two wear-tests (NPT1,DT15) and two major life demonstration tests (LDT, TTT) are the focal point of the ground test program. The first three tests employ EMTs and BBPPUs while the final life and throttling demonstration will use hardware, fabicated by HEDD, that will have undergone protoflight qualification environmental tests.

Based on the experience gained in the ground test program, the in-space segment of the NSTAR Thruster/Power Processor Element involves the HEDD build of a Pathfinder (precursor) thruster, two each of flight ion thrusters, PPUs, DCIUs, and cable harnesses. Flight ion thruster design is derived from the second EMT which is now in the Life Demonstration Test. The flight thruster design was driven primarily by the structural and thermal requirements. The flight PPU design, driven by high efficiency requirements for solar array bus voltages from $80 \mathrm{~V}$ to $160 \mathrm{~V}$, has slightly different requirements than the initial breadboard PPU whose development started in 1993. The DCIU provides for initiation of thruster operation, throttling, xenon flow control, data, and recovery from fault conditions. The flight thruster, PPU, and DCIU will be integrated and will undergo acceptance tests prior to delivery to DS1 facility where the PPU, DCIU, and Pathfinder Thruster will be acceptance tested at the spacecraft level. During the course of the DS1 mission, a diagnostics package will use a quartz crystal microbalance, solar absorptance measurements, plasma probes, magnetometers, and a plasma wave antenna to document NSTAR system contamination, communications impacts, and electromagnetic interference ${ }^{8}$. DS1 spacecraft systems will provide propulsion subsystem information related to thrust, thrustvector, and compatibility with spacecraft systems.

The NSTAR schedule (Figure 3) shows that the breadboard PPUs and EMTs were built and functionally tested over the 1993-1997 period. Random vibration, thermal-vacuum, plume, and communication impact tests were also conducted over that period. Wear- and life-tests are ongoing throughout the program. As shown in the schedule, the flight hardware will be delivered to the DS1 integration and test program in October 1997.

\section{The Ion Propulsion System on DS1}

The NSTAR hardware will provide primary propulsion for the Deep Space 1 spacecraft. Figure 4 shows a schematic of the DS1 spacecraft with the approximate location of the ion thruster mounted in a double-ring gimbal assembly. The thruster is recessed within the conic-section of the spacecraft structure and is thermally isolated from the spacecraft. The NSTAR PPU is located on the opposite end of the spacecraft. The PPU wall thickness is sized to minimize the risk of micrometeroid penetration. As indicated in Figure 4, the DCIU and the xenon feed system are located on the outside of the spacecraft structure. The power cable has ringterminals at the PPU and thruster and intermediate connectors are used to simplify both the installation and testing procedures. The overall NSTAR subsystem dry mass, including thruster, PPU, DCIU, cables, and the xenon storage/feed system, is about $47 \mathrm{~kg}$ including contingency. The maximum tankange capability for the xenon propellant is about $81 \mathrm{~kg}$. The DS1 spacecraft wet mass is expected to be approximately $500 \mathrm{~kg}$.

\section{Thruster Element Ground Test Program}

The NSTAR ground test program included NASA's development of engineering model thrusters and breadboard PPUs prior to initiating a contract for flight hardware. The purpose of the preflight activity was to clearly define thruster and PPU operational, performance, and lifetime requirements. EMTs were evaluated during the course of design verification, wear, and environmental tests. BBPPUs were formally integrated with EMTs and were used in the 8000 hour Life Demonstration Test.

\section{Engineering Model Thruster}

Figure 5 is a schematic of the $30 \mathrm{~cm}$ diameter EMT used in the ground test program. The thruster is comprised of four major subassemblies: the discharge cathode-keeper electrode assembly, the discharge chamber which is at anode potential, the ion optics comprised of a positive screen grid and a negative accelerator grid, and the neutralizer assembly. The basic development of the thruster is described in References 4,9 , and 10 . The discharge chamber of 
the first EMT was primarily fabricated from spun-formed aluminum except for the downstream piece which was formed from titanium in order to adequately support the ion optical system. Ion optics and hollow cathode heritage was basically derived from the $30 \mathrm{~cm}$ diameter mercury thruster development program ${ }^{3}$. Cathode and heater designs were developed under the NASA Research and Technology Program, and protocols for cathode flight hardware were strongly based on the work of the Plasma Contactor Development Program ${ }^{7}$ for the International Space Station. A ring-cusp magnetic circuit was used in the EMT ${ }^{4}$. Samarium-cobalt magnets form of rings of alternating polarity along the discharge chamber. There are three magnet rings, one in the region of the main cathode, one ring at the conic-cylinder intersection, and one at the ion optics end. The overall mass of the first EMT was about $6.4 \mathrm{~kg}$, much of which was the $1.9 \mathrm{~kg}$ ion optical system. Thruster mass did not include high-voltage propellant electrical isolators, wire-mesh for sputtered material control, or an electric terminal assembly.

Table 2 is a brief description of the evolution of the EMT design. Design changes were incorporated as a result of wear measurements made after the 2000 hour test. Additional thruster modifications were made to accommodate random vibration and thermal vacuum requirements. The first changes were made after screen grid (positive grid) and main hollow cathode assembly wear was experienced during the 2000 hour test. For subsequent tests, the screen grid was referenced to cathode potential, rather than floating, to control the potenial drop in the vicinity of the grid, a cathode keeper electrode was added to mitigate cathode orifice plate erosion, and discharge chamber surface treatments were added to retain sputtered material and control the size of flakes that might spall $^{10,11}$. EMT4 incorporated most of the important features that will be found in the flight thruster. EMT4 attributes include titanium internal to the discharge chamber, wire-mesh throughout the discharge chamber, a discharge keeper electrode, and grit-blasted components to increase radiation heat transfer.

\section{The Breadboard Power Processor}

The BBPPUs are comprised of four power supplies whose basic functions and operation are described in References 12 and 13. The blockdiagram of Figure 6 illustrates the architecture of the BBPPU. Power was provided to the PPU via two separate power buses, a 28 VDC regulated bus which powered all housekeeping functions including the microcontroller, and an 80 to 120 VDC high-power bus which supplied power to the four power converters which operated the thruster. The discharge and neutralizer power supplies employed a dual-use topology to allow the cathode heater powers to be derived from the same converter which supplied power to the main and neutralizer keeper discharges, respectively. The discharge and neutralizer power supplies had maximum current capabilities of about $15 \mathrm{~A}$ and $9 \mathrm{~A}$, respectively. The beam and accelerator power supplies were separate physically but were controlled in unison during thruster operation. The beam power supply had a 1100 VDC, 1.8 A capability. For a given throttle setpoint, the beam current was controlled via a closed-loop to the main discharge current. Flow rates were fixed for a given throttle setpoint. A microcontroller was used to automate the cathode conditioning, thruster start, and steady-state operation of the thruster. Fifteen pre-programmed throttle levels were available for thruster operation and were stored internal to the microcontroller. A single command was available to start the thruster and maintain steady-state operation at any of these power levels. The data in the throttling table were modifiable by another command. Controlled parameters and five thruster power levels used in the throttle table for functional tests are shown in Table 3. Cathode and main flow rates ranged from $2.1 \mathrm{sccm}$ to $3.7 \mathrm{sccm}$ and 6.0 to $23.5 \mathrm{sccm}$, respectively. If the flow rates were set to those used at the maximum power level, the thruster could be ramped from the lowest to the highest throttle level in less than 3 minutes. The microcontroller also digitized all analog power supply outputs and power supply status bits and transmitted the telemetry data over a RS-232 data link to a command and telemetry display terminal. A typical test configuration for the BBPPU is shown in Figure 7. The functional/integration tests validated that the BBPPU satisfactorily ignited discharges, controlled the thruster over 15 throttle levels with power over-shoot $<1 \%$, and performed all highvoltage fault-detection and recovery sequences as required. Two BBPPUs were built by NASA, integrated with EMTs, and made available for use in the LDT.

\section{Development Tests}

Table 1 generally describes some of the major development and wear-tests conducted by the NSTAR Project to date. Only three of the most critical development tests will be described here. These tests were a part of the thruster design verification related to performance 
characterization, structural integrity, validation of a thruster thermal model, and temperature margins for thermally sensitive magnets in the discharge chamber.

The Performance Acceptance Tests were initially performed in a large space simulation testbed ${ }^{9}$ at LeRC to characterize BOL data and later to assess performance trends during the course of wear-tests. The PAT data set consisted of six power levels ranging from $2.3 \mathrm{~kW}$ down to about $0.5 \mathrm{~kW}^{14}$. Table 4 summarizes the BOL PAT test results at $2.3 \mathrm{~kW}$ and at minimum power levels. At $2.3 \mathrm{~kW}$, the main discharge plenum, main cathode, and neutralizer xenon flow rates were $23.3 \mathrm{sccm}, 3.0 \mathrm{sccm}$, and $3.0 \mathrm{scccm}$, respectively. The controlled parameters were beam power supply voltage, beam current with a feed-back loop to the discharge current, accelerator voltage, neutralizer keeper current, and the propellant flow rates. Thruster performance was determined using calculations described in Reference 4. BOL performance data were obtained for the four EMTs. At full-power, the thrust and efficiency of the four EMTs varied by $\pm 1.1 \%$ and $\pm 2.9 \%$, about the average, respectively. From PATs of EMT2 at LeRC and JPL, it was found that the thrust calculated from measurements at separate facilities differed by $<0.5 \%$ at $2.3 \mathrm{~kW}$ and $<2 \%$ at $0.5 \mathrm{~kW}$. This indicates excellent transportability of thruster performance data.

Only two of the other development tests (Table 1), the random vibration test and the DS1 thermal vacuum simulation test, will be described because they had significant influence on the EMT design. Random vibration tests of EMT1c were conducted by HEDD to establish confidence in the EMT design approach. Based on earlier diagnostic sine vibration tests of EMT1b, and other structural considerations, the basic design of EMT1b was altered to include three aluminum gimbal brackets rather than two stainless steel brackets, a new neutralizer mounting bracket similar to the aluminum gimbal bracket, and a compression-loaded alumina-based electrical insulator assembly rather than polymer insulators which isolate the brackets from the high-voltage discharge chamber. These changes were incorporated into EMT1c. The thruster was mounted to the shaker table by a set of six struts. EMTlc was subjected to random vibration levels of $-6 \mathrm{~dB}$ and $-3 \mathrm{~dB}$ from protoflight levels for DS1 spacecraft hardware, and finally to the protoflight vibration input of $13 \mathrm{~g}_{\mathrm{rms}}$. Table 5 shows the random vibration test requirements for acceptance and protoflight qualification tests ${ }^{15}$. The thruster was vibrated in all three axes, and diagnostic sine sweeps of $0.5 \mathrm{~g}$ amplitude were taken over the specified frequency range of $20 \mathrm{~Hz}$ to $2000 \mathrm{~Hz}$ before and after each test to determine any changes in the natural frequencies. The first six modes generally resulted in translation or rocking with frequencies from $77 \mathrm{~Hz}$ to $170 \mathrm{~Hz}$. The EMT successfully completed the $13 \mathrm{~g}_{\mathrm{rms}}$ random vibration tests. Pre- and post-random vibration test sine survey diagnostics indicated changes to the natural frequencies were $<4 \%$. Based on these test results, the basic thruster design was deemed to be acceptable. Because there was a change in the DS1 gimbal design and the thruster mounting struts or brackets, another series of vibration tests of EMT1c is planned prior to testing the flight thruster.

The purpose of the DS1 thermal simulation test (DT2d) was to thermally evaluate EMT4. EMT4 had internal discharge chamber components which were fabricated from titanium, and the thruster had a flight-like, adiabatic thermal interface consistent with the DS1 configuration. Potential over-heating of the thruster samariumcobalt magnets was the major concern for this test. The thruster was mounted to a simulated gimbal assembly which in tum was attached to a cylindrical shroud simulating the DS1 spacecraft structure (Figure 8). The outer side of the base of a cylindrical can, which simulated the DS1 adiabatic interface, was blanketed with 10layers of aluminized Mylar with fiber separators. There was a high-emissivity coating on the inner side of the can base. The outer surface of the shroud was enclosed in a coil circulating hot-water which simulated expected temperatures in the DS1 cavity. Another 10-layer thermal blanket was placed over this coil. A total of 26 thermocouples monitored the experiment which was conducted in LeRC's Vacuum Facility 5 whose vacuum level was $5 \times 10^{-6}$ Torr at full-power operation. With the thruster off, the shroud temperature was about $53{ }^{\circ} \mathrm{C}$ which is the expected upper bound of the spacecraft outer surface temperature. The adiabatic can temperature was $-36^{\circ} \mathrm{C}$. At the fullpower, $2.3 \mathrm{~kW}$ condition, the test yielded magnet temperatures of $288{ }^{\circ} \mathrm{C}, 250^{\circ} \mathrm{C}$, and $289^{\circ} \mathrm{C}$ for the cathode, middle, and downstream magnet rings, respectively. These temperatures are considerably less than the upper limit magnet temperature of $350{ }^{\circ} \mathrm{C}$. Even though the EMT4 cathode assembly is less conductive thermally than the flight thruster, and the gimbal bracket assembly was stainless steel/polymer insulators versus titanium/alumina insulators for the flight design, the test results indicate there is 
considerable magnet temperature margin. A thruster thermal model, developed by R. A Becker of JPL, is being used to assess impacts of EMT4 versus flight thruster design changes in the DS1 environment.

\section{Wear-Tests}

The NSTAR ground test program involves four long-term tests to validate the ion propulsion subsystem designs. Wear- and life-tests of 2000 hours $^{9}$ and 1000 hours $^{10}$ have been completed, and an 8000 hour Life Demonstration Test is underway. All these tests were conducted at the full-power level of $2.3 \mathrm{~kW}$. An extended Thruster Throttling Test is planned for CY1998.

2000 Hour Test A 2000 hour test of EMT1a was conducted in a large space simulation facility at LeRC and three potential failure mechanisms of the EMT were identified ${ }^{9}$. After a test interruption at $876 \mathrm{~h}$, erosion of the main cathode orifice plate, heater, and radiation shield was observed. The main cathode assembly was replaced, and the test resumed until it was voluntarily terminated after a total time of $2030 \mathrm{~h}$ In order to minimize ion erosion of the discharge cathode, it was decided to install a cylindrical keeper electrode for subsequent EMTs. A $1000 \mathrm{ohm}$ resistor was connected between the keeper and the anode to preclude PPU design changes. At full-power the keeper operates at about $5 \mathrm{~V}$ above cathode potential.

Charge exchange ion erosion of the accelerator grid was of concern prior to the test, but extrapolated results indicated that the accelerator grid life was substantially greater than the $12,000 \mathrm{~h}$ full-power qualification test requirement. Ion erosion of the center of the screen (positive) grid was $\sim 100 \mu \mathrm{m}$ which was about $25 \%$ of the grid thickness. The high erosion was due to the fact that the screen grid was allowed to float electrically, and the discharge main flow rate was too low. This condition produced a higher discharge voltage, higher doubly-charged xenon ion production, and with the grid floating a few volts negative of cathode potential the high screen grid erosion rate could readily be explained. Subsequent EMTs have the screen grid electrically tied to cathode potential. Because of the relatively high molybdenum efflux from the screen grid, films deposited on surfaces in the vicinity of the grid were found to spall. In-space migration of flakes could cause internal thruster electrical shorts or defocussed ion beamlets which can produce accelerator grid erosion ${ }^{16}$. Subsequent EMTs employ discharge chamber surface treatments in the form of wire mesh or gritblasted surfaces ${ }^{3,11}$ to securely retain sputtered films. A thruster perfomance augmentation option was also exercised at this point by reducing the diameter of the neutralizer hollow cathode orifice thereby extending the stable operating range to lower flow rates especially at low power levels ${ }^{17}$.

1000 Hour Test Thruster hardware changes were made to EMT1a resulting in EMT1b (Table 2) which was put into a $1000 \mathrm{~h}$ revalidation test at JPL ${ }^{10}$. The test was operated at the full-power level of $2.3 \mathrm{~kW}$. Table 6 shows the nominal thruster operating parameters. Figure 9 shows that the average thruster performance showed very little variation with test time. The small, cyclic variations of the data are due to day/night temperature effects on flow rates. The discharge chamber propellant efficiency was 0.89 , and this resulted in a low discharge voltage, low doubly-charged xenon ion production, and a maximum screen grid erosion on centerline of only $6 \mu \mathrm{m} / \mathrm{kh}$. This low screen grid erosion rate implies relatively thin molybdenum coatings on the discharge chamber walls. After the test, there was no evidence of spalled flakes. Independent thermal-cycling and stress tests of molybdenum coatings on treated discharge chamber material substrates indicated no spalling problems for film thicknesses up to $30 \mu \mathrm{m}$. If the worst-case deposition rates observed in the 1000 hour test were used to extrapolate coating thickness to the qualification test life of 12,000 hours, the coating thickness would be well below $30 \mu \mathrm{m}$.

It was found that the main cathode orifice plate, heater and radiation shield were adequately protected by the keeper electrode which operated about $4.6 \mathrm{~V}$ above cathode potential. Erosion of the cathode assembly components were virtually undetectable using a micrometer and a scanning electron microscope measurements method.

Average accelerator pit and groove erosion rates ${ }^{10}$, in the center of the grid, were $\sim 77 \mu \mathrm{m} / \mathrm{kh}$ and $13 \mu \mathrm{m} / \mathrm{kh}$, respectively. These erosion rates include the effects of operating at non-space like vacuum conditions which could increase erosion rates ${ }^{18}$ and effects of carbon deposition on the accelerator grid from sputtered facility surfaces. The latter effect could also reduce erosion rates compared to in-space conditions. Given the magnitude of these erosion rates and the fact that the pit erosion rate will likely decrease with time because of molybdenum deposition on pit walls, it lends confidence that the accelerator grid structural 
integrity will not be an issue at the full-power of $2.3 \mathrm{~kW}$ for much more than $12,000 \mathrm{~h}^{10}$.

The Life Demonstration Test Because accurate extrapolation of wear-rates and thuster reliability from the $2000 \mathrm{~h}$ and $1000 \mathrm{~h}$ tests to the fullpower service lifetime is difficult, an $8000 \mathrm{~h}$ LDT using EMT2 (Tables 1 and 2) was planned. Some of the major objectives of the test are to demonstrate $8000 \mathrm{~h}$ of stable operation of the EMT, identify life-limiting phenomena, measure performance of EMT2 over the $0.5 \mathrm{~kW}$ to $2.3 \mathrm{~kW}$ throttling range at $1000 \mathrm{~h}$ intervals, measure in situ wear rates of the accelerator grid, and verify earlier lifetime estimates. EMT2 was operated at $2.3 \mathrm{~kW}$ using the BBPPU, a power console, and a laboratory xenon feed system. Test diagnostics included a direct thrust measurement, beam probes, two quartz crystal microbalances, a magnetometer, and EMI instrumentation. Also included was a laser profilometer which was used to obtain in situ measurements of the features of the accelerator grid's pit and groove erosion ${ }^{10}$.

The LDT was initiated in June of 1996 at JPL's $3 \mathrm{~m}$ diameter by $10 \mathrm{~m}$ long vacuum chamber ${ }^{10}$. Hollow cathode and main plenum flow rates were held constant throughout the test. At this writing, EMT2 has accumulated over $6000 \mathrm{~h}$ of stable operation. The beam current has been controlled to $\sim 1.76 \mathrm{~A}$ while the discharge current has increased from $12.5 \mathrm{~A}$ at $\mathrm{BOL}$ to about 15.2 A at $6000 \mathrm{~h}$ to maintain the fixed beam current. Much of the discharge current increase can be attributed to accelerator grid aperture wear which increases the neutral losses, and thus higher discharge power is required to maintain the ion beam current at fixed flow rates. The slight opening of the accelerator grid apertures during the test is supported by a measured increase in ion optics perveance margin of $160 \mathrm{~V}$ at full-power. Over the course of the test, the discharge voltage was in the $23.5 \mathrm{~V}$ to $25.0 \mathrm{~V}$ range. The neutralizer keeper current was fixed at $1.5 \mathrm{~A}$. Neutralizer keeper voltage and coupling voltage variations over the test were only $14.3 \mathrm{~V}$ to $13.0 \mathrm{~V}$ and $13.5 \mathrm{~V}$ to $12.6 \mathrm{~V}$, respectively. At the nominal $2.3 \mathrm{~kW}$ input power level, the thrust was about $93 \mathrm{mN}$, and the specific impulse was $3160 \mathrm{~s}$. The direct thrust measurements were usually 1.00 to 1.02 times the calculated values.

The accelerator grid current at BOL was $\sim 8.5 \mathrm{~mA}$ and dropped to an asymptotic level of about $6 \mathrm{~mA}$ after $1400 \mathrm{~h}$. The ratio of accelerator to beam current was about $0.34 \%$ which is higher than the nominal $0.24 \%$ obtained when a $30 \mathrm{~cm}$ diameter mercury ion thruster was life tested at low background pressures ${ }^{14}$. This implies it is likely that charge exchange ion production rates in the vicinity of the accelerator grid are higher in this test than would be experienced in a space environment. Results of profilometer measurements, taken each $1000 \mathrm{~h}$, indicate the average accelerator grid pit and groove erosion rates at the center of the grid are about $30 \mu \mathrm{m} / \mathrm{kh}$ and $6 \mu \mathrm{m} / \mathrm{kh}$, respectively. The "groove" erosion rate was derived from the minimum eroded depth in the bridges ${ }^{19,20}$ between two holes. Linear extrapolations of the profilometer data indicate the grid wear is acceptable to periods well in excess of the qualification test lifetime of $12,000 \mathrm{~h}$. These accelerator grid wear data are consistent with an empirical correlation of local erosion rate with thruster parameters ${ }^{20}$.

LDT results to date indicate stable thruster operation over the $0.5 \mathrm{~kW}$ to $2.3 \mathrm{~kW}$ input power range, very small variations in performance parameters, and no evidence of phenomena that would preclude thruster lifetimes in excess of $12,000 \mathrm{~h}$ at $2.3 \mathrm{~kW}$. More detailed results of this test will be reported in August 1997.

Thruster Throttling Test The TTT is scheduled for CY1998 and will be the first extended test of the HEDD-built flight thruster, PPU, and DCIU. The objective of the test is to demonstrate $150 \%$ of the required total impulse $(2.7 \mathrm{x}$ $10^{6} \mathrm{Ns}$ ) during the course of a throttling sequence which could simulate a suitable mission profile. The thrust subsystem will demonstrate stable, long-term operation at specified throttled conditions. In situ beam diagnostics and wear assessments will be made during the test. The hardware to be tested will be the second flight set which will have undergone protoflight qualification tests including functional, vibration, EMI, and thermal-vacuum tests. An engineering model xenon storage and feed system will be used in the TTT.

\section{NSTAR Thruster Element Flight Hardware}

Figure 10 shows a diagram of the principal elements of the thrust subsystem namely, the PPU, DCIU, the ion thruster, and the Xenon Feed System. The feed system has two pressure switch/valve/plenum legs from a common storage tank. One leg provides flow to the cathodes, and the other provides flow to the main discharge plenum ${ }^{21}$. Three propellant feed lines and the power cables are terminated within the thruster plasma screen. Two avionics boxes, the PPU and DCIU, are shown in 
Figure 10. The DCIU provides supervisory control of the Thruster Element, controlling the XFS and the PPU. The DCIU monitors and regulates the pressures in the XFS plena, operating the valves as necessary to provide regulated xenon flow to the thruster. The power supplies in the PPU are also controlled by the DCIU, as the PPU contains only output fault protection logic and does not have automatic thruster control capability as a stand alone unit. The PPU enclosure houses three power supply modules which convert the spacecraft bus power to the levels necessary to operate the thruster. The PPU also has local analog to digital and digital to analog capability on the "slice" circuit board which is used for telemetry digitization and power supply control based on DCIU commands. These functions are powered from an auxiliary 22-34 VDC power bus, which allows for the acquisition of PPU telemetry while the PPU is in a standby mode, or is disconnected from the main power bus.

The contract with HEDD calls for the delivery of a Pathfinder thruster, two flight thrusters, two PPUs, 2 DCIUs, and two thruster/PPU wire harnesses. Prior to production of flight hardware, a HBBPPU and an EMDCIU were developed and integrated with other subsystems. The Pathfinder Thruster is a presursor to the flight units and is used to define assembly procedures, perform functional and thermal-vacuum tests, and also will go through the DS1 integration and environmental test program. The flight thruster is one of the last components integrated onto the DS1 spacecraft.

\section{Major Design Requirements}

Thruster, PPU, and DCIU design requirements are described in detail in the NSTAR Thruster Element Technical Requirements Document ${ }^{22}$, and only a few of the performance and environmental requirements will be summarized here. The thruster is designed for throttling over a $0.5 \mathrm{~kW}$ to $2.3 \mathrm{~kW}$ power range. Projected values of thrust and thruster efficiency at $2.3 \mathrm{~kW}$ are $92 \mathrm{mN}$ and 0.64 , respectively. At $0.5 \mathrm{~kW}$, the values of thrust and efficiency are expected to be in excess of $19.5 \mathrm{mN}$ and 0.38 , respectively. The thruster will generate a total impulse of greater than $2.7 \times 10^{6} \mathrm{Ns}$ for any mission power profile. This capability results in a xenon thoughput of approximately $83 \mathrm{~kg}$. The thruster mass is specified at less than $8.2 \mathrm{~kg}$ with a cylindrical envelope less than $50 \mathrm{~cm}$ diameter by $44 \mathrm{~cm}$ long. The thuster will have three gimbal pads, and the actual thrust vector alignment is expected to be within an $18 \mathrm{mrad}$ tolerance.
The PPU is designed to operate from a $80 \mathrm{~V}$ to $160 \mathrm{~V}$ high-power bus with control and telemetry functions powered from a $22 \mathrm{~V}$ to $34 \mathrm{~V}$ low-power bus. Minimum power processor efficiences at the output power extremes are specified as 0.90 at $2.3 \mathrm{~kW}$ and 0.84 at $0.5 \mathrm{~kW}$. The low-power bus is expected to provide $<20 \mathrm{~W}$ to the PPU and $<30$ to the DCIU. Many of the component requirements were driven by the New Millennium DS1 Component and Spacecraft Verification Specification ${ }^{15}$.

The thruster, DCIU, and PPU structural designs were guided by the random vibration profiles shown in Table 5. The overall random vibration level for the acceptance tests is $9.2 \mathrm{~g}_{\mathrm{rms}}$. Each component (e.g. thruster) will be vibrated at the component and spacecraft levels. The thruster random vibration test will employ a simulator of the DS1 gimbal assembly. Flight acceptance shock requirements for the thruster, PPU and DCIU are ar 330,1330 , and $2500 \mathrm{~g}$-peak, respectively, at frequencies of $1500 \mathrm{~Hz}$ and $10,000 \mathrm{~Hz}$. Significant attenuation of these levels is expected because of component location and mounting geometries.

The flight allowable thermal requirements are shown in Table $7^{22}$. The thruster cold-soak temperature is as low as $-93^{\circ} \mathrm{C}$. At full-power the thruster reference temperature at the mask, which is the downstream portion of the plasma screen is $138{ }^{\circ} \mathrm{C}$, and the maximum temperature of the discharge chamber surface is typically $-300{ }^{\circ} \mathrm{C}$, but may range between values of and $300{ }^{\circ} \mathrm{C}$ to $350{ }^{\circ} \mathrm{C}$. The maximum allowable temperature for the samarium-cobalt magnets is $350^{\circ} \mathrm{C}$. The DS1 spacecraft will ensure the DCIU and PPU baseplate temperatures will be kept below $50^{\circ} \mathrm{C}$ while the thruster is operating. Minimum flight allowable temperatures for the DCIU and PPU are $-15{ }^{\circ} \mathrm{C}$ and $-5{ }^{\circ} \mathrm{C}$, respectively. The DCIU and PPU boxes were designed to a radiation hardening level of $100 \mathrm{kRad}$ which is a maximum dose rate imposed on many Earth-orbiting spacecraft electronic subsystems. This specification is much higher than radiation doses to be encountered during the DS1 mission. Some of the more detailed functions of the DCIU and PPU are described in the following two paragraphs.

DCIU Functions The DCIU is the central data acquisition and control system for the thruster element. DCIU power is drawn from the spacecraft 22 to 34 VDC auxilary power bus. The primary DCIU functions are:

- Execute stored operating sequences in response to ground commands 
- Control XFS and PPU transitions to the commanded operating mode and state

- Control XFS solenoid and latch valves

- Control PPU power supplies

- Regulate thruster xenon flow and input power to one of sixteen stored operating points

- Receive, store, and process PPU telemetry data via the "slice" circuit board located within the PPU

- Acquire, store, and process XFS telemetry

- Provide a command and telemetry interface via a MIL-STD-1553B data bus

- Provide a serial data link for each connected PPU

- Support a maximum of eight thruster/PPU combinations

- Detect and respond to a limited number of thruster fault types

These functions are performed via DCIU hardware and software capability and will be discussed in the flight hardware design sections that follow. Table 8 lists the design resource allocations for the DCIU with regard to physical size and power.

PPU Functions The PPU provides power to the thruster and the "slice" board. The "slice" circuit board is located in the PPU and is used for telemetry digitization and power supply control based on commands from the DCIU. Thruster power is derived from an 80 to 160 VDC bus, while housekeeping power is taken from the spacecraft 22 to 34 VDC auxiliary power bus. PPU input power requirements are listed in Table 9. The wide range of PPU input voltage was selected to accommodate large variations in solar array power that are a result of the large variations in distance from the sun on planetary trajectories. The design resource allocations for the PPU are listed in Table 10. The number in parenthesis is the mass for the DS1 configuration. The additional $1.7 \mathrm{~kg}$ is micrometeroid shielding required due to the location of the PPU on the ram side of the spacecraft.

Thruster power is provided via six power supply outputs from three inverter modules. The output specifications are as listed in Table 11. The PPU is internally protected from input bus under and overvoltage conditions on both power busses. Output power ranges from 0.5 to $2.3 \mathrm{~kW}$ and is set via the DCIU through power supply setpoints and xenon flow rates to the thruster. All power supplies are short-circuit protected and the PPU contains all logic necessary to recover from thruster short circuits.

\section{Flight Hardware Design}

Thruster Design The NSTAR thruster design was derived from the EMT. Some changes in materials and geometry were made to accommodate specific structural and thermal design requirements. Items retained from the EMT were the basic main discharge and neutralizer hollow-cathodes, the ion optical system, the magnetic circuit, the plasma screen, and the spun-formed discharge chamber concept. The basic NSTAR thruster is shown in Figure 11. In the early EMTs (Table 1), five of the six discharge chamber structural elements were made from aluminum. For structural and thermal reasons, all discharge chamber sheet-metal parts, the three gimbal-brackets, and the neutralizer mounting bracket will now be made from titanium. Concerns about polymer creep resulted with a change of the polymer mounting insulators to an alumina-based mounting insulator design. Minor changes were made to the propellant isolator design to enhance the thermal and electrical integrity. The three internal propellant lines of the thruster will be completely welded construction except for three fittings that terminate them in the vicinity of the neutralizer assembly. A newly designed wire harness terminal assembly will be located in the neutralizer housing. The thruster power cables, in the form of two bundles, exit the neutralizer housing and are terminated at the DS1 gimbal bulkhead using two electrical connectors. A PPU cable harness is connected at the bulkhead to complete the power circuit.

DCIU Design The DCIU was implemented using half width VME bus circuit boards. Three boards are present in the DS1 configuration, but the DCIU enclosure has capacity sufficient for up to five boards if necessary. The three boards used are a processor board, data acquisition board and a valve driver board.

The processor board utilizes an $80 \mathrm{C} 86$ rad-hard microprocessor operating at a clock speed of $4 \mathrm{Mhz}$. 64k of Electrically Eraseable Programmable Read Only Memory is present to store the flight software. and $64 \mathrm{k}$ of Static Random Access Memory is used for software execution. In addition to the microprocessor and memory, a MIL-STD-1553 chip set is present to facilitate communication with the host spacecraft. RS422 drivers are also present for communication with up to eight PPUs. 
The data acquisition board provides for up to 64 multiplexed analog inputs with 12 bit analog to digital conversion resolution. In addition, the board houses a precision $1 \mathrm{~mA}$ current source for use with Resistance Thermometer Devices in the xenon feed system. Precision, temperature compensated resistors are also present for self-calibration of the temperature readings and to detect any post-launch offsets that may occur in the circuitry.

The valve driver board contains 14 optically isolated valve drivers which can be used with either solenoid or latching valves in the XFS. In addition to the valve drivers, $a \pm 15$ VDC and 5 VDC output DC/DC converter is present to provide internal DCIU housekeeping power. As shown in Figure 10, XFS valve and pressure transducer power is also routed through the DCIU and is not counted in the DCIU power budget. Radiation hardened CMOS technology is used throughout the DCIU, with a minimum $100 \mathrm{kRad}(\mathrm{Si})$ specification for all parts, with spot shielding used where required. The flight software requirements are extensive. These requirements and the design execution will be synopsized in a later section

PPU Design Spacecraft power is input to the PPU via two power busses, an 80 to 160 VDC high power bus and a 22 to 34 VDC auxiliary or housekeeping bus as listed in Table 9. Both input busses have Electromagnetic Interference filters to ensure compliance with the conducted emission requirements of MIL-STD-461. The low power bus drives a housekeeping conveter which provides control power for the PPU power supplies and the "slice" board. The housekeeping converter has undervoltage lockout capability and can operate with input voltages as high as $60 \mathrm{VDC}$.

The $80-160 \mathrm{~V}$ bus is distributed from the input EMI filter to three inverters which provide the six power outputs needed for thruster operation as listed in Table 11. The final EMI filter capacitance is distributed among these three inverter inputs to improve EMI filter performance and reduce switching transients at the inverter power stages. The switching frequency for these three inverters is $20 \mathrm{kHz}$.

The beam power supply is made up of four $\mathrm{H}$ bridge stages with their outputs connected in series as shown in Figure 12. Each stage is capable of $600 \mathrm{~V}$ output at $160 \mathrm{VDC}$ input at an output power level of $1 \mathrm{~kW}$. The four stages are controlled via a four-level pulse width modulation scheme where only one of the inverters operates at a reduced duty cycle while the other three inverters operate at $100 \%$ duty cycle or are completely off.

The discharge inverter also utilizes an H-Bridge power stage, and is comprised of a single stage as shown in Figure 13. The output filter is a single inductor with a pulse generating winding. For cost control and manufacturability, the discharge power stage and the four beam supply inverters utilize identical transformer cores, transistors, and bracketry.

The third and final inverter provides the cathode and neutralizer heater, accelerator, and neutralizer keeper outputs (Figure 14). A novel HBridge arrangement is used where the two top transistors of the bridge are operated at $50 \%$ duty cycle. The four outputs are generated with separate transformers connected to the top two transistors through steering diodes. Pulse width modulation is accomplised via four separate sets of bridge transistors connected to the power transformers.

Software The NSTAR thruster element is designed for autonomous operation via the $\mathrm{DCrU}$ software. The DCIU has several automatic and manual modes that are entered via commands received through the 1553 data bus. The primary automatic modes are standby, cathode conditioning, thruster ignition and steady-state operation, throttling, and grid clearing. During all thruster modes, telemetry is acquired and broadcast back to the spacecraft at the rate of 1 frame/second. The telemetry list is too extensive for inclusion herein, but contains all power supply outputs, thruster floating potential, XFS temperatures and pressures, PPU temperatures, digital status words, and mode indicators.

Standby mode allows the PPU and DCIU to be powered and broadcasting telemetry, while not operating the thruster, for health and status purposes. The cathode conditioning mode is a onetime procedure used to prepare the thruster cathodes for operation after exposure to air or contaminating environments. This mode is entered into via command. Thruster ignition is an automatic procedure where the DCIU receives a command to operate the thruster at one of the sixteen programmed power levels. Upon receipt of the command the DCIU sets the feed system to supply flow to the thruster at the flow rate listed in the throttle table for that power level. Discharge cathode and neutralizer flows are raised for ignition and are adjusted to the values in the table after ignition. Flow rates are set based on flow control device temperature and a corresponding plenum pressure which is computed by the DCIU. After starting flow rates 
have been established, the thruster cathodes are heated and the neutralizer and main discharge are lit, followed by the application of the high voltage to the ion optics. Power supply setpoints at ignition are set to $4 \mathrm{ADC}$ of discharge curent, and the accelerator and beam power supplies are set to 150 and $650 \mathrm{~V}$, respectively. The resultant beam current is about 0.5 ADC. After the thruster is operational the beam and accelerator power supplies are ramped to the levels indicated in the throttle table and then the closed loop beam current algorithm is used to adjust the beam current to the level indicated in the table. The closed loop algorithm operates by varying the discharge current until the resulting beam current is desired. A simple proportional algorithm is used with a maximum allowable adjustment of discharge current of $100 \mathrm{~mA} /$ second. Grid clearing, in the event a flake temporarily shorts the grids, is accomplished by the switching of the output of the discharge power supply to the ion optics via relays and commanding the discharge power supply on. Power is left on until the short is cleared or thirty seconds has elapsed.

The flight software also allows for the manual operation of all power supplies and XFS valves. New flight code can be uploaded and the sixteen throttle table setpoints can be reprogrammed via command. All thruster parameters are subject to limit checking, and out of tolerance flags are set in the event of an out of limit excursion of a telemetry parameter. The thruster can also be throttled in real time via command, and a restart is not necessary. Thruster arc events, which result in momentarily reducing the discharge current and recycling the highvoltage power supplies, are automatically recovered from and counted. In the event continuous recycling is detected, the thruster discharge current is commanded to the $4 \mathrm{~A}$ level, and the system is allowed to return to low power operation via the closed-loop control algorithm. The thruster will then be slowly ramped to the previous throttle setpoint. In the event that the recycling continues, the thruster is shut down and an error flag set in telemetry which activates a ground alarm.

\section{Development Testing}

A breadboard PPU with flight circuits (HBBPPU) was integrated with an engineering model thruster at LeRC. Thruster operation was stable over the full input voltage range and output power range. High voltage faults were simulated, and no anomalies were noted. PPU efficiency was measured and found to be in excess of the contract specifications of 0.90 and
0.84 at output power levels of $2.3 \mathrm{~kW}$ and $0.5 \mathrm{~kW}$, respectively.

A number of development tests involving the HBBPPU, the EMDCIU, and an engineering model feed system are either ongoing or planned in the very near future. Such tests include:

- Stability test using a solar array simulator, HBBPPU, and EMT4 (JPL).

- Integration test of the EMDCIU and the XEM (JPL).

- An end-to-end test of a solar array simulator, EMDCIU, HBBPPU, an XEM, and EMT4 (JPL).

- Thermal-vacuum tests of the Pathfinder Thruster (LeRC).

- Random vibration tests of EMT1c with a thruster gimbal assembly simulator (HEDD).

In-process tests and acceptance tests of the flight hardware are scheduled for the August/September 1997 period.

\section{Concluding Remarks}

The NSTAR Project has demonstrated ion thruster life and reliability in ground tests and is in the process of assembling a flight qualified thruster, power processor and a controller for the Deep Space 1 spacecraft. As a part of the ground test program, NASA has built four engineering model thrusters and two breadboard power processing units. Thrusters and BBPPUs have been integrated, and an extensive set of development and characterization tests have been performed. Some of the development tests involved EMT performance sensitivity at various throttle setpoints, direct thrust measurements, measurement of external magnetic fields, ion beam impacts on communication signals, thruster cold-soak tests, and a high temperature test of EMT4 with a simulated DS1 spacecraft thermal interface. Additionally, an EMT successfully completed a random vibration test at protoflight qualification levels. The selection of the flight thruster discharge chamber material, and the design of the neutralizer mounting bracket and gimbal pad assembly were dictated by the results of the environmental developments tests. A significant number of components were grit-blasted to enhance radiation heat transfer. 
Design verification tests of $2000 \mathrm{~h}$ and $1000 \mathrm{~h}$ have been completed. After the $2000 \mathrm{~h}$ test, four design changes were required, namely, to electrically tie the screen grid to cathode potential to reduce grid erosion, to add a discharge keeper electrode to reduce cathode erosion, to add discharge chamber treatments to retain sputtered films, and to reduce the diameter of the neutralizer hollow cathode orifice to enhance power and propellant efficiencies at low power levels. The $1000 \mathrm{~h}$ revalidation test gave confidence to our estimates of wear-rates and lifetime projections. Further validation of thruster life is ongoing via the $8000 \mathrm{~h}$ Life Demonstration Test. As of this writing, more than $6000 \mathrm{~h}$ have been successfully demonstrated. Results to date indicate stable thruster operation over the throttling range with small variations in performance parameters. In situ accelerator grid erosion measurements were consistent with earlier projected wear-rates which indicated grid lifetimes well in excess of the $12,000 \mathrm{~h}$ qualification test requirement.

Detailed design requirements for the flight thruster, PPU, and DCIU have been developed to satisfy propulsion needs for a wide class of planetary spacecraft. The thruster is capable of being throttled over a $0.5 \mathrm{~kW}$ to $2.3 \mathrm{~kW}$ power range. The flight thruster design was derived from the EMT and results of the EMT environmental tests. The DCIU provides data acquisition and system control via processor, data acquisition, and valve driver boards. The PPU will operate from a $80 \mathrm{~V}$ to $160 \mathrm{~V}$ power bus. A breadboard PPU, which is an electrical equivalent of the flight unit, successfully completed an integration test with EMT3. Subsystem performance and high voltage fault data were taken, and no anomalies were noted. More extensive stability and end-to-end tests are scheduled using a solar array simulator with the BBPPU, the EMDCIU, and EMT4. The flight thruster, PPU, and DCIU are now being assembled in preparation for integration, functional, and flight acceptance tests at the component level.

\section{Acknowledgements}

The authors would like to acknowledge the valuable fabrication and test support provided by LeRC's Test Installations Division as well as the support from the test installations staff at JPL. The support from NSTAR Project members including John Stocky (JPL), Frank Curran (LeRC), Michael Marcucci, David Brinza, Robert Gounley, Henrik Gronroos, Roy Kakuda,
Stan Krauthamer, Sun Matsumoto, Marge Ruppel, and James Tribbett all of JPL, James Parkes of NYMA, Inc., and Roger Myers previously of NYMA Inc. is gratefully acknowledged.

\section{$\underline{\text { References }}$}

1. Kakuda, R., Sercel, J., and Lee, W., "Small Body Rendezvous Mission Using Solar Electric Ion Propulsion: Low Cost Mission Approach and Technology Requirements," IAA Paper L-0710, April 1994.

2. Burrows, W. E., "The New Millennium," Air and Space, August/September 1996, pp. 4453.

3. Anon., "30-Centimeter Ion Thrust Subsystem Design Manual," NASA TM 79191, 1979.

4. Patterson, M. J., Haag, T. W., and Hovan, S. A., "Performance of the NASA $30 \mathrm{~cm}$ Ion Thruster," IEPC Paper 93-108, September 1993.

5. Brophy, J. R., et al., "Segmented Ion Engine Operation and Performance," AIAA Paper 94-2851, June 1994.

6. Beattie, J. R., Williams, J. D., and Robson, R. R., "Flight Qualification of an $18-\mathrm{mN}$ Xenon Ion Thruster," IEPC Paper 93-106.

7. Patterson, M. J., et al., "Plasma Contactor Development for Space Station," IEPC Paper 93-246, September 1993.

8. Brinza, D. E., Personal Communication, JPL, Pasadena, CA, November 1996.

9. Patterson, M. J., et al., " $2.3 \mathrm{~kW}$ Ion Thruster Wear Test," AIAA Paper 95-2516, July 1995.

10. Polk, J. E., et al., "A 1000-Hour Wear Test of the NASA NSTAR Ion Thruster," AIAA Paper 96-2717, July 1996.

11. Power, J. L. and Hiznay, D. J., "Solutions for Discharge Chamber Sputtering and Anode Deposit Spalling in Small Mercury Ion Thruster," NASA TM X-71675, March 1975.

12. Hamley, J. A., et al., "A $2.5 \mathrm{~kW}$ Power Processor for the NSTAR Ion Propulsion Experiment," AIAA Paper 94-3305, July 1994.

13. Hamley, J. A., et al., "Development Status of the NSTAR Ion Propulsion System 
Power Processor," AIAA Paper 95-2517, July 1995.

14. Rawlin, V. K., "Power Throttling the NSTAR Thruster," AIAA Paper 95-2515, July 1995.

15. Hall, W. T., "Component and Spacecraft Verification Specification for New Millennium Program's Deep Space No. 1," Spectrum Astro, Inc. Document No. 1069-EWQ00108 Revision B, April 1997.

16. Collett, C., et al., "Thruster Endurance Test," NASA CR-135011, May 1976.

17. Patterson, M. J. and Mohajeri, K., "Neutralizer Optimization," NASA TM105578 , October 1991.
18. Rawlin, V. K., "Characterization of Ion Accelerating Systems on NASA's Ion Thrusters," AIAA Paper 92-3827, July 1992.

19. Rawlin, V. K., "Erosion Characteristics of Two-Grid Ion Accelerating Systems," IEPC Paper 93-175, September 1993.

20. Patterson, M. J., Haag, T. W., Rawlin, V. K., and Kussmaul, M. T., "NASA 30-cm Ion Thruster Development Status," AIAA Paper 94-2849, June 1994.

21. Engelbrecht, C., Personal Communication, JPL, Pasadena, CA, November 1996.

22. Hamley, J. A., "NSTAR Thruster Element Technical Requirements Document," ND310, JPL-D-13638, April 1997.

Table 1. Major development. characterization, and wear-tests.

\begin{tabular}{|c|c|c|}
\hline Test ID & Description & Purpose \\
\hline PATs & $\begin{array}{l}\text { Performance acceptance tests of } 4 \\
\text { EMTs }\end{array}$ & Obtain performance dispersion data. Scc Table 4. \\
\hline NPT1 & 2000 hour wear-test & EMT design verification \\
\hline DT9b & Low power test & Demonstrate $870 \mathrm{~h}$ of stable operation at $530 \mathrm{~W}$ \\
\hline DT15 & 1000 hour wear-test & Validation test of EMT2 after design changes \\
\hline FITA & $\begin{array}{l}\text { Functional integration test of the } \\
\text { LeRC BBPPUs }\end{array}$ & $\begin{array}{l}\text { Integrate BBPPU1 with EMT2 and BBPPU2 with } \\
\text { EMT4 }\end{array}$ \\
\hline CT19 & $\begin{array}{l}\text { Performance sensitivity test of } \\
\text { EMT2 }\end{array}$ & $\begin{array}{l}\text { Obtain thruster performance sensitivity to allowed } \\
\text { variations at selected throttle setpoints }\end{array}$ \\
\hline DT7b & External magnetic field & $\begin{array}{l}\text { External magnetic field measurements to provide to } \\
\text { spacecraft personncl }\end{array}$ \\
\hline LDT & Life Demonstration Test & $\begin{array}{l}\text { Validatc performance and life at } 2.3 \mathrm{~kW} \text { for } 8000 \\
\text { h. }\end{array}$ \\
\hline DT5b & Thrust measurement & Direct thrust measurcment using EMT4 \\
\hline CT6 & Single plenum test & $\begin{array}{l}\text { Characterize thruster performance using only one } \\
\text { of the two XFS flow legs. }\end{array}$ \\
\hline DT3a & $\begin{array}{l}\text { Functional integration test of the } \\
\text { HEDD BBPPU }\end{array}$ & Integrate the BBPPU (flight circuits) with EMT3 \\
\hline DT14a & Communication impacts tests & $\begin{array}{l}\text { Assess ion beam impacts on communications } \\
\text { signals }\end{array}$ \\
\hline DTIb & Random vibration test & $\begin{array}{l}\text { Structural integrity test of EMTlc to DSI } \\
\text { qualification test levels }\end{array}$ \\
\hline DT2a, b & Thruster cold soak tests & Cold soak EMT3 to DS I qualification test levels \\
\hline DT2d & DS1 thermal simulation & $\begin{array}{l}\text { Thermal vacuum test of EMT4 with simulation of } \\
\text { the DSI spacecraft. }\end{array}$ \\
\hline TTT & Thruster Throttling Test & $\begin{array}{l}\text { Use flight hardware to validate performance and life } \\
\text { over a given mission profile. }\end{array}$ \\
\hline
\end{tabular}


Table 2. Evolution of the EMT design.

\begin{tabular}{l|l|l|l|l|l|l|l|}
\hline Major Features & EMT1a & EMT1b & EMT1c & EMT2 & EMT3 & EMT4 & Flight \\
\hline Major test & $2030 \mathrm{~h}$ & $1000 \mathrm{~h}$ & $\begin{array}{l}\text { Random } \\
\text { vibration }\end{array}$ & $8000 \mathrm{~h}$ & $\begin{array}{l}\text { Thermal } \\
\text { vacuum }\end{array}$ & $\begin{array}{l}\text { Thermal } \\
\text { vacuum }\end{array}$ & Flight \\
\hline $\begin{array}{l}\text { Main cathode } \\
\text { keeper electrode? }\end{array}$ & No & Yes & Mass model & Yes & Yes & Yes & Yes \\
\hline $\begin{array}{l}\text { Discharge chamber } \\
\text { material (internal) }\end{array}$ & Al/Ti & Al/Ti & Al/Ti & AlTi & Al/Ti & Ti & Ti \\
\hline $\begin{array}{l}\text { Wire-mesh } \\
\text { throughout } \\
\text { discharge chamber? }\end{array}$ & No & Partial & Partial & Partial & Yes & Yes & Yes \\
\hline $\begin{array}{l}\text { Gimbal bracket } \\
\text { material }\end{array}$ & $\begin{array}{l}\text { Stainless } \\
\text { steel }\end{array}$ & $\begin{array}{l}\text { Stainless } \\
\text { steel }\end{array}$ & Al & $\begin{array}{l}\text { Stainless } \\
\text { steel }\end{array}$ & $\begin{array}{l}\text { Stainless } \\
\text { steel }\end{array}$ & $\begin{array}{l}\text { Stainless } \\
\text { steel }\end{array}$ & Ti \\
\hline $\begin{array}{l}\text { Grit-blast } \\
\text { components for } \\
\text { emissivity control? }\end{array}$ & No & No & No & No & Yes & Yes & Yes \\
\hline $\begin{array}{l}\text { Lightening holes in } \\
\text { some discharge } \\
\text { chamber } \\
\text { components? }\end{array}$ & No & No & Yes & No & Yes & Yes & Yes \\
\hline
\end{tabular}

Table 3. Thruster parameters controlled during functional test throttling.

\begin{tabular}{|l|l|l|l|l|l|}
\hline Power to thruster, $\mathrm{kW}$ & 2.31 & 2.06 & 1.48 & 1.00 & 0.49 \\
\hline & & & & & \\
\hline Beam power supply voltage, $\mathrm{V}$ & 1100 & 1100 & 1100 & 1100 & 650 \\
\hline Accelerator power supply voltage, $\mathrm{V}$ & 180 & 180 & 180 & 150 & 150 \\
\hline Beam current, $\mathrm{A}$ & 1.76 & 1.58 & 1.09 & 0.72 & 0.50 \\
\hline Discharge plenum flow, sccm & 23.5 & 21.3 & 14.3 & 9.0 & 6.0 \\
\hline Discharge cathode flow, sccm & 3.00 & 2.48 & 2.10 & 2.10 & 2.10 \\
\hline Neutralizer flow, sccm & 3.00 & 2.48 & 2.10 & 2.10 & 2.10 \\
\hline Neutralizer keeper current, A & 1.5 & 1.5 & 1.5 & 2.0 & 2.0 \\
\hline Maximum discharge voltage, V & 28.0 & 28.0 & 28.0 & 29.0 & 30.0 \\
\hline
\end{tabular}


Table 4. Summary of Performance Acceptance Test data for the EMTs at $2.3 \mathrm{~kW}$ and $0.5 \mathrm{~kW}$

\begin{tabular}{|l|l|l|l|l|l|l|l|l|}
\hline Parameter & EMT1b & EMT1b & EMT2 & EMT2 & EMT3 & EMT3 & EMT4 & EMT4 \\
\hline & & & & & & & & \\
\hline Power, kW & 2.30 & 0.52 & 2.27 & 0.52 & 2.24 & 0.53 & 2.31 & 0.53 \\
\hline Flowrate, mg/s & 2.90 & 1.01 & 2.87 & 1.00 & 2.87 & 1.00 & 2.89 & 1.01 \\
\hline & & & & & & & & \\
\hline $\begin{array}{l}\text { Beam power supply } \\
\text { voltage, V }\end{array}$ & 1100 & 650 & 1100 & 650 & 1100 & 650 & 1101 & 650 \\
\hline Beam current, A & 1.78 & .54 & 1.76 & .54 & 1.75 & .55 & 1.74 & 0.53 \\
\hline Discharge voltage, V & 24.9 & 28.0 & 25.8 & 29.0 & 26.0 & 29.9 & 25.8 & 28.5 \\
\hline Discharge current, A & 11.6 & 4.5 & 11.5 & 4.9 & 10.5 & 4.7 & 12.8 & 4.8 \\
\hline Accelerator voltage, V & 180 & 150 & 180 & 150 & 180 & 151 & 181 & 151 \\
\hline Accelerator current, mA & 8.3 & 1.4 & 7.3 & 1.3 & 7.0 & 2.2 & 15.3 & $2.6(1)$ \\
\hline $\begin{array}{l}\text { Neutralizer keeper } \\
\text { voltage, V }\end{array}$ & 13.1 & 18.0 & 14.3 & 19.7 & 14.6 & 20.7 & 15.0 & 24.5 \\
\hline $\begin{array}{l}\text { Neutralizer keeper } \\
\text { current, A }\end{array}$ & 2.0 & 2.0 & 1.5 & 1.5 & 1.5 & 1.5 & 1.5 & 2.0 \\
\hline Coupling voltage, V & -12.3 & -10.7 & -13.7 & -12.9 & -13.7 & -13.4 & -13.3 & -11.5 \\
\hline & & & & & & & & \\
\hline Thrust, mN & 94 & 22 & 92 & 22 & 92 & 22 & 92 & 21 \\
\hline Specific impulse, s & 3300 & 2200 & 3270 & 2200 & 3270 & 2240 & 3240 & 2140 \\
\hline Thruster efficiency & 0.657 & 0.455 & 0.651 & 0.446 & 0.658 & 0.457 & 0.630 & 0.420 \\
\hline
\end{tabular}

(1) Data were taken at higher vacuum chamber pressure.

Table 5. Random vibration requirements for the flight thrusters

\begin{tabular}{|c|c|c|c|c|c|}
\hline $\begin{array}{l}\text { Conditions for } \\
\text { all axes }\end{array}$ & Frequency. $\mathrm{Hz}$ & $\begin{array}{l}\text { Power spectral } \\
\text { density, } \mathrm{g}^{2} / \mathrm{Hz}\end{array}$ & $\begin{array}{l}\text { Slope. } \\
\text { dB/octave }\end{array}$ & Overall $g_{r m}$ & $\begin{array}{l}\text { Duration. } \\
\text { s/axis }\end{array}$ \\
\hline Protoflight & $\begin{array}{l}20-50 \\
50-500 \\
500-2000 \\
\end{array}$ & $\begin{array}{l}- \\
0.2 \\
- \\
\end{array}$ & $\begin{array}{l}+6 \\
- \\
-6 \\
\end{array}$ & 13 & 60 \\
\hline Acceptance & $\begin{array}{l}20-50 \\
50-500 \\
500-2000\end{array}$ & $\begin{array}{l}\overline{-} \\
0.1 \\
-\end{array}$ & $\begin{array}{l}+6 \\
- \\
-6 \\
\end{array}$ & 9.2 & 60 \\
\hline
\end{tabular}


Table 6. Average value of operating and performance parameters during the $1000 \mathrm{~h}$ test. (Reference 10)

\begin{tabular}{|l|l|}
\hline Parameter & Average value \\
\hline Beam power supply voltage, V & \\
\hline Beam current, A & 1103 \\
\hline Discharge voltage, V & 1.76 \\
\hline Discharge current, A & 24.3 \\
\hline Accelerator power supply voltage, V & $13.4(1)$ \\
\hline Accelerator power supply current, mA & 180 \\
\hline Neutralizer keeper voltage, V & 7.76 \\
\hline Neutralizer keeper current, A & 4.6 \\
\hline Coupling voltage, V & 1.51 \\
\hline Discharge plenum flowrate, sccm & -13.3 \\
\hline Discharge cathode flowrate, sccm & 23.5 \\
\hline Neutralizer flowrate, sccm & $3.75(1)$ \\
\hline & $3.70(1)$ \\
\hline Power, kW & \\
\hline Thrust, mN & 2.30 \\
\hline Specific impulse, s & 92.9 \\
\hline Efficiency & 3110 \\
\hline Estimated Xe + Xe ${ }^{+}$on centerline & 0.617 \\
\hline
\end{tabular}

(1) During flowmeter calibration prior to the test, a silicone hose leaked xenon via diffusion resulting in higher flowrates than desired compared to the PAT setpoints of Table 4 . This resulted in lower discharge voltage, higher discharge current, lower production of doubly charged xenon ions, and slightly lower efficiency and specific impulse compared to the $2000 \mathrm{~h}$ test and the PAT data.

Table 7. Flight allowable reference temperatures for the thruster. PPU, and DCIU. (Temperatures in "C)

\begin{tabular}{|l|l|l|l|l|}
\hline & $\begin{array}{l}\text { Non-operating. } \\
\text { cold }\end{array}$ & Operating. cold & Operating. hot & Non-operating, hot \\
\hline & & & & \\
\hline $\begin{array}{l}\text { Thuster } \\
\text { temperature on the } \\
\text { mask (1) }\end{array}$ & -93 & -93 & 138 & 138 \\
\hline PPU baseplate & -25 & $-5(2)$ & 50 & 55 \\
\hline DCIU baseplate & -25 & -15 & 50 & 55 \\
\hline
\end{tabular}

(1) The mask is the downstream portion of the plasma screen. The mask covers the periphery of the accelerator grid.

(2) DSI heater operation is required at the low throttle levels.

Note also: (a) PPU and DCIU temperature transition rates will be less than 1 " $\mathrm{C} / \mathrm{min}$.

(b) Thruster non-operating hot temperatures are turn-off and not tum-on conditions. 
Table 8. DCIU resource allocation.

\begin{tabular}{|l|l|l|}
\hline & Specification & Actual \\
\hline & & \\
\hline Mass, $\mathrm{kg}$ & 2.4 & 2.4 \\
\hline Envelope, $\mathrm{cm}$ & $15 \times 22 \times 13$ & $14.6 \times 18.5 \times 12.7$ \\
\hline Input voltage, $\mathrm{V}$ & 22 to 34 & 22 lto 34 \\
\hline Input power, $\mathrm{W}$ & $<30$ & $<8$ \\
\hline
\end{tabular}

Table 9. PPU input power requirements.

\begin{tabular}{|l|l|l|}
\hline & High power bus & Low power bus \\
\hline & & \\
\hline Input voltage, V & 80 to 160 & 22 to 34 \\
\hline Input current, $\mathrm{A}$ & 32 maximum & 1 nominal \\
\hline EMI specification & MIL-STD-461 & MIL-STD-461 \\
\hline Inrush protection & None & None \\
\hline Grounding & $\begin{array}{l}\text { Negative or float to }<5 \mathrm{~V} \text { from } \\
\text { chassis }\end{array}$ & $\begin{array}{l}\text { Negative or float to }<5 \mathrm{~V} \text { from } \\
\text { chassis }\end{array}$ \\
\hline
\end{tabular}

Table 10. PPU resource allocation.

\begin{tabular}{|l|l|l|}
\hline & Specification & Actual \\
\hline Mass, $\mathrm{kg}$ & & \\
\hline Envelope, cm & $\begin{array}{l}12(13.7 \text { with micrometeroid } \\
\text { protection) }\end{array}$ & $12(13.7)$ \\
\hline Output power, W & $38 \times 51 \times 8$ & $38 \times 51 \times 8$ \\
\hline Efficiency & 0.5 to 2.3 & 0.5 to 2.3 \\
\hline & 0.90 at $2.3 \mathrm{~kW}$ output & 0.92 at $2.3 \mathrm{~kW}$ \\
& 0.84 at $0.5 \mathrm{~kW}$ & 0.86 at $0.5 \mathrm{~kW}$ \\
\hline
\end{tabular}


Table 11. PPU output specifications for the fight hardware.

\begin{tabular}{|l|l|l|l|l|l|}
\hline & Beam & Accelerator & Discharge & Neutralizer & Cathode heaters \\
\hline $\begin{array}{l}\text { Output voltage, } \\
\mathrm{V}\end{array}$ & 650 to 1100 & 150 to 250 & 15 to 35 & 8 to 32 & 3 to 12 \\
\hline $\begin{array}{l}\text { Output curtent, } \\
\text { A }\end{array}$ & 0.5101 .8 & 0 to 0.2 & 41014 & 1 to 2 & 3.5 to 8.5 \\
\hline Regulation & $\begin{array}{l}\text { Constant } \\
\text { current }\end{array}$ & $\begin{array}{l}\text { Constant } \\
\text { voltage }\end{array}$ & $\begin{array}{l}\text { Constant } \\
\text { current }\end{array}$ & $\begin{array}{l}\text { Constant } \\
\text { current }\end{array}$ & $\begin{array}{l}\text { Constant } \\
\text { current }\end{array}$ \\
\hline Output ripple & $\begin{array}{l}<5 \% \text { of } \\
\text { setpoint }\end{array}$ & $\begin{array}{l}<5 \% \text { of } \\
\text { setpoint }\end{array}$ & $\begin{array}{l}<5 \% \text { of } \\
\text { setpoint }\end{array}$ & $\begin{array}{l}<5 \% \text { of } \\
\text { setpoint }\end{array}$ & $\begin{array}{l}<5 \% \text { of } \\
\text { setpoint }\end{array}$ \\
\hline $\begin{array}{l}\text { Line/Load } \\
\text { regulation }\end{array}$ & $<5 \%$ & $<5 \%$ & $<5 \%$ & $<5 \%$ & $<5 \%$ \\
\hline Isolation. V & $>2 \mathrm{kV}$ & $>2 \mathrm{kV}$ & $>2 \mathrm{kV}$ & $>2 \mathrm{kV}$ & $>2 \mathrm{kV}$ \\
\hline
\end{tabular}

\begin{tabular}{|l|l|}
\hline & Pulse ignitors (2) \\
\hline & \\
\hline Peak voltage, V & 650 \\
\hline Duration. $\mu \mathrm{s}$ & 10 \\
\hline Slew rate. $\mathrm{V} / \mu \mathrm{s}$ & 150 \\
\hline Frequency, $\mathrm{Hz}$ & $>10$ \\
\hline
\end{tabular}

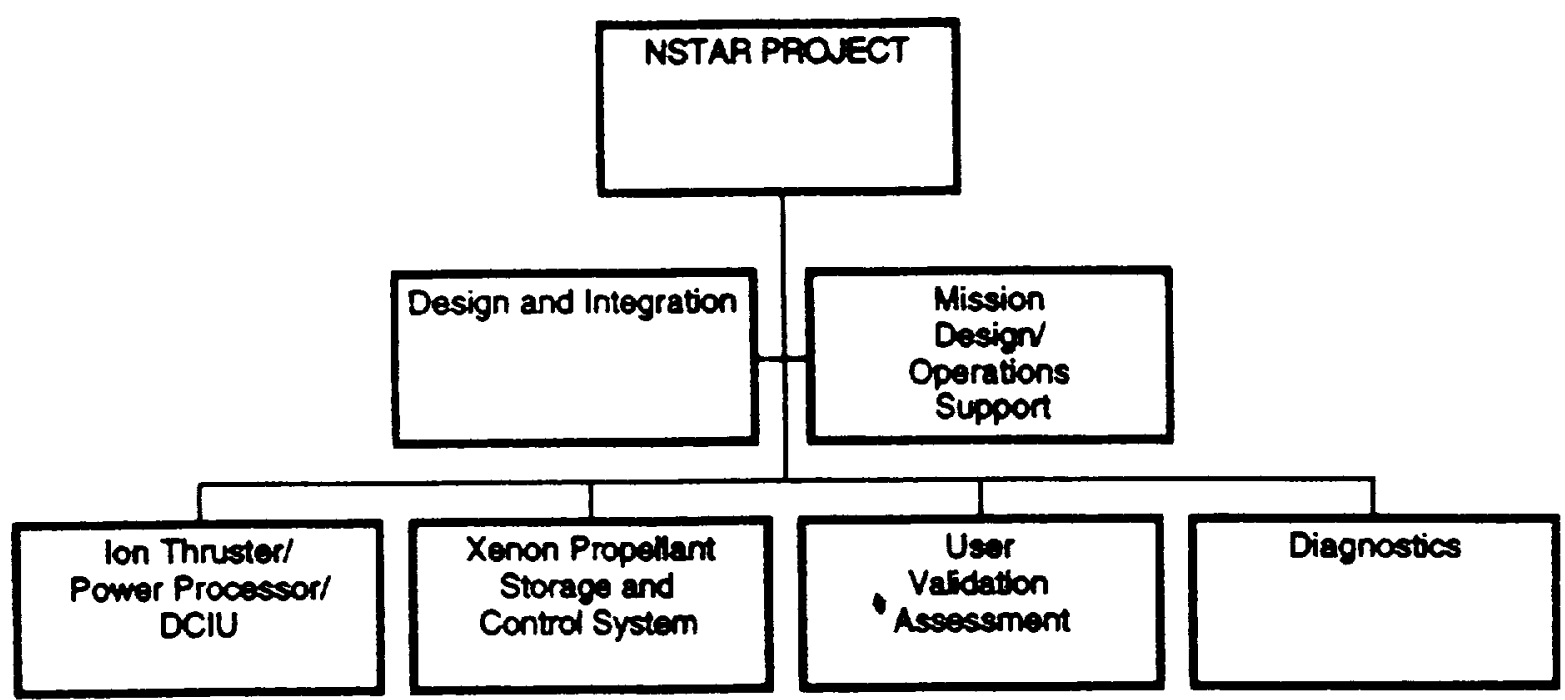

Figure 1.-NSTAR Project block diagram. 


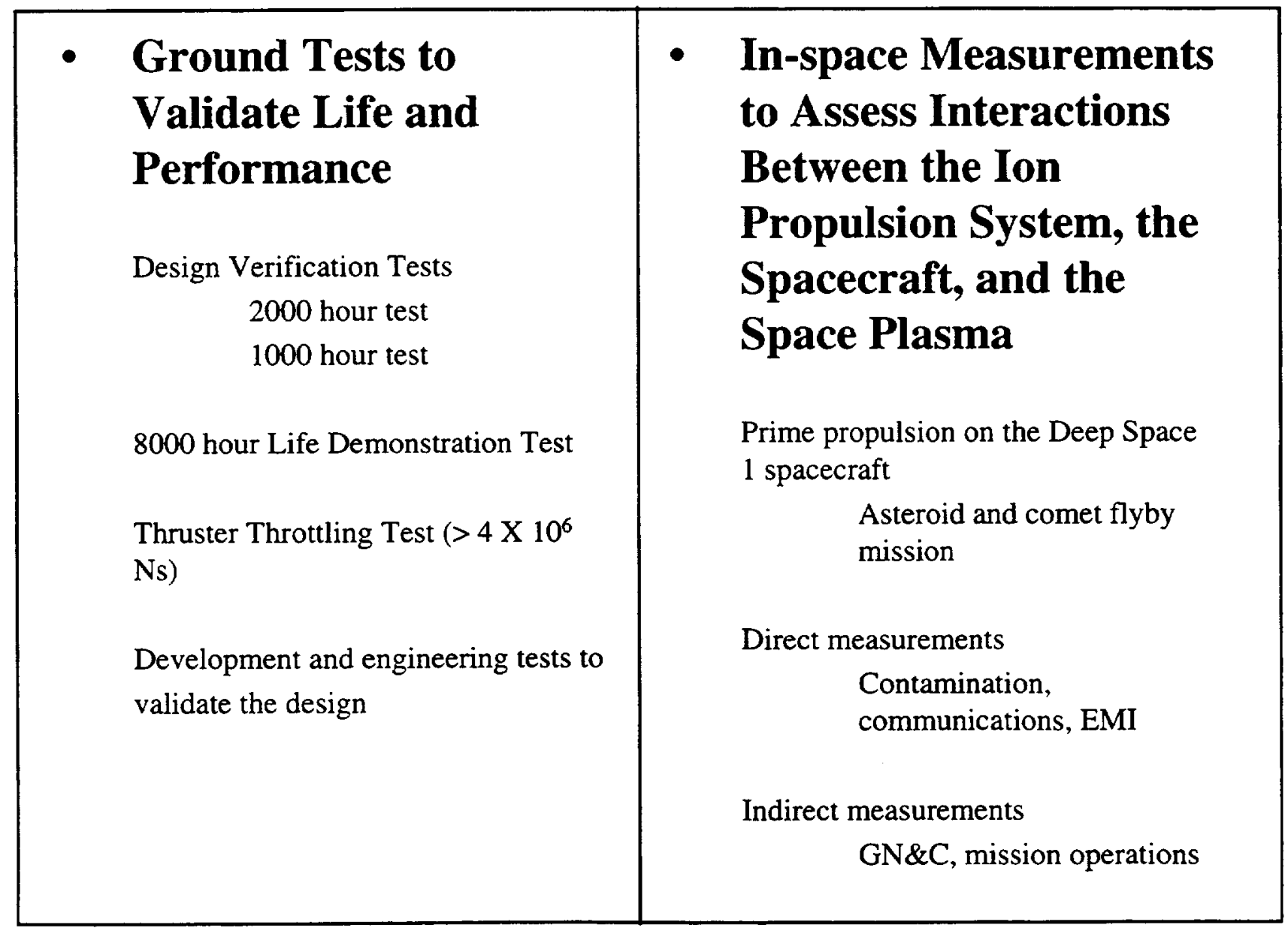

Figure 2.-Major elements of the NSTAR program. 


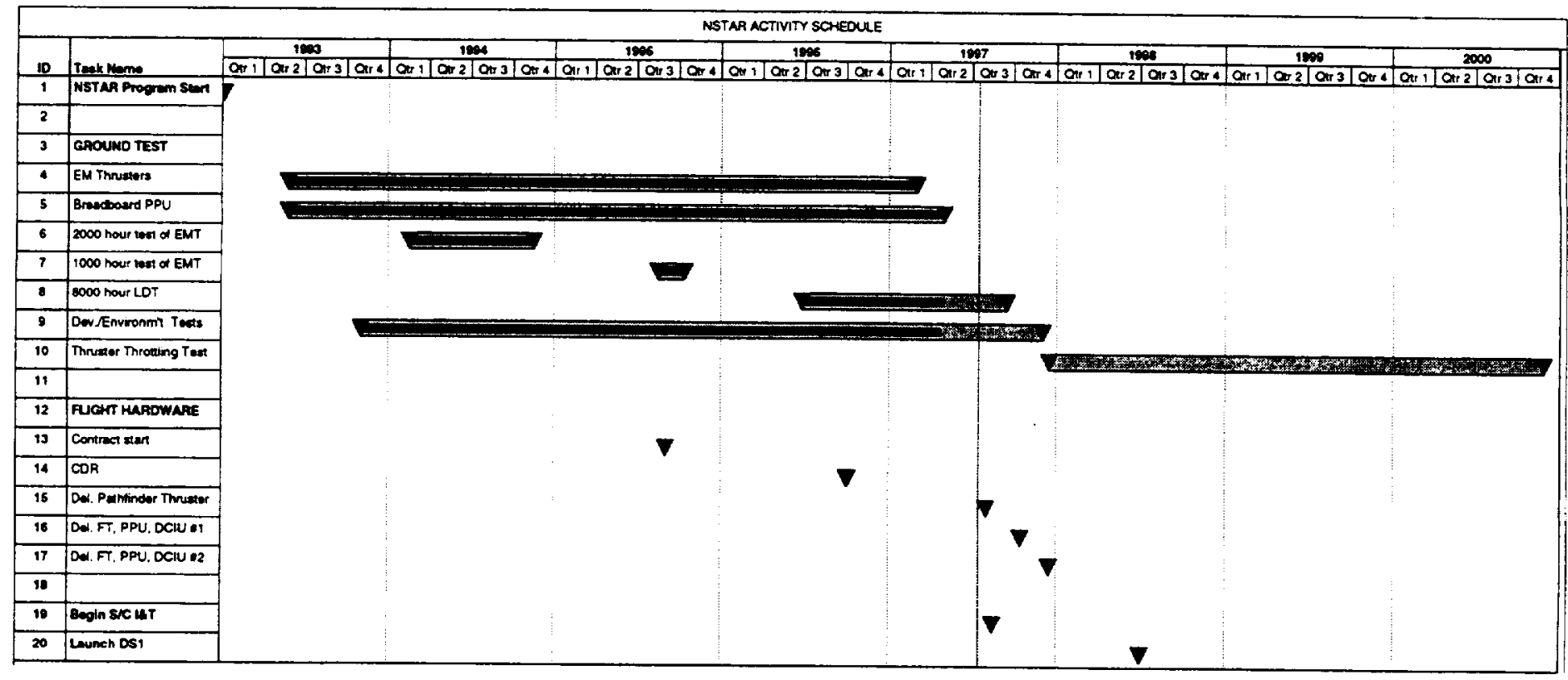

Figure 3.-NSTAR schedule.

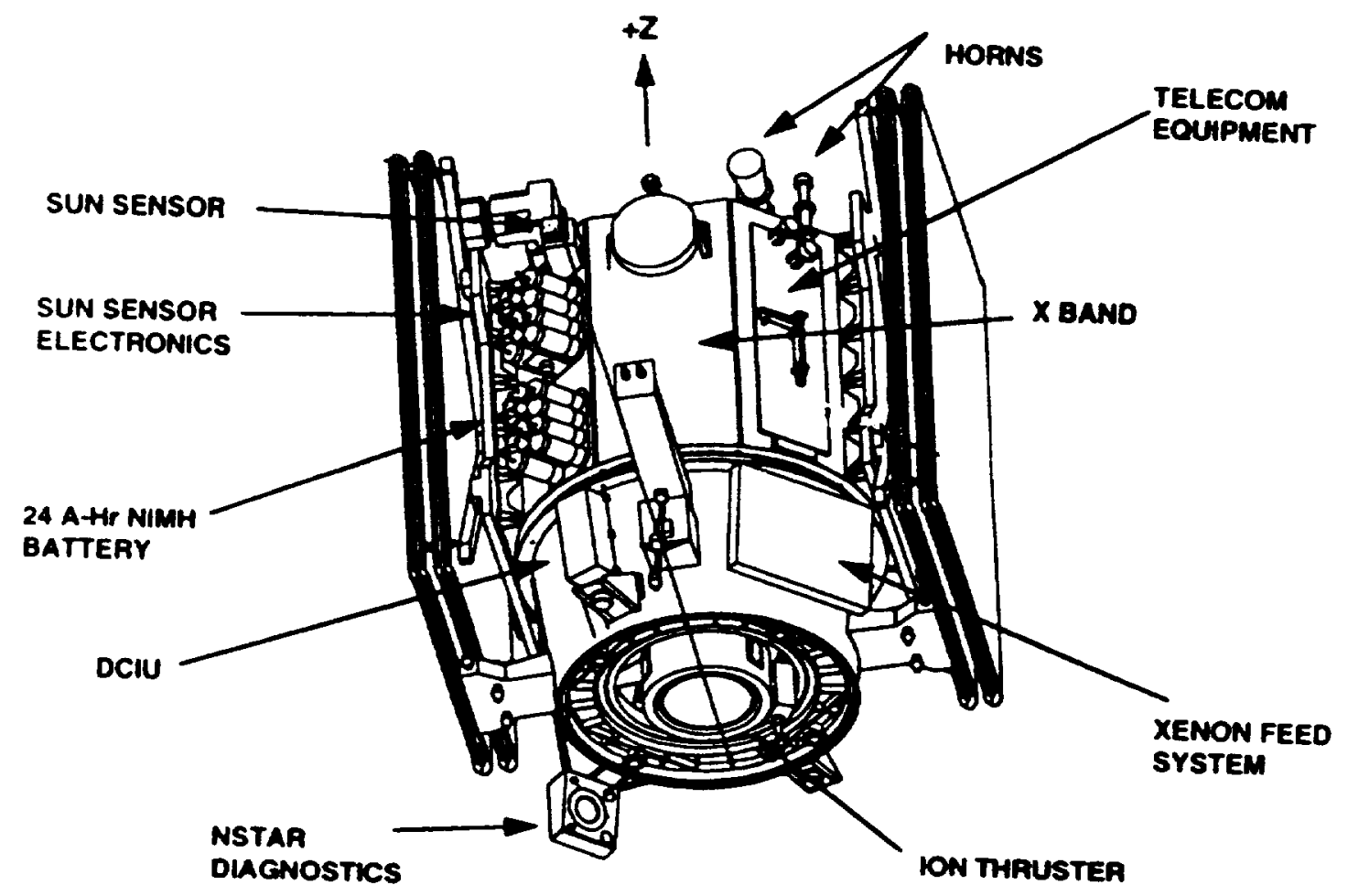

Figure 4.-The DS1 spacecraft showing thruster location. 


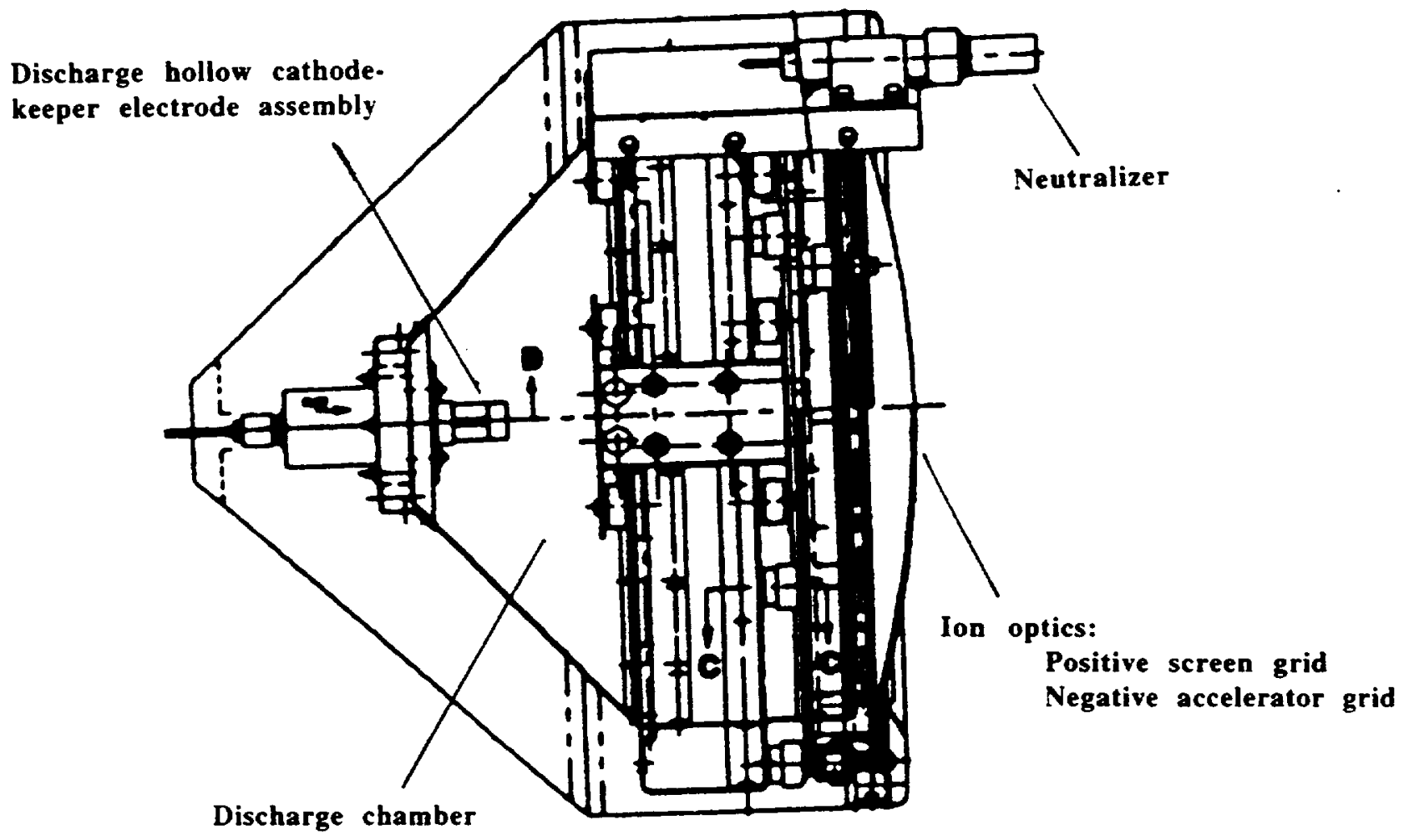

Figure 5.-Schematic of the Engineering Model Thruster. 


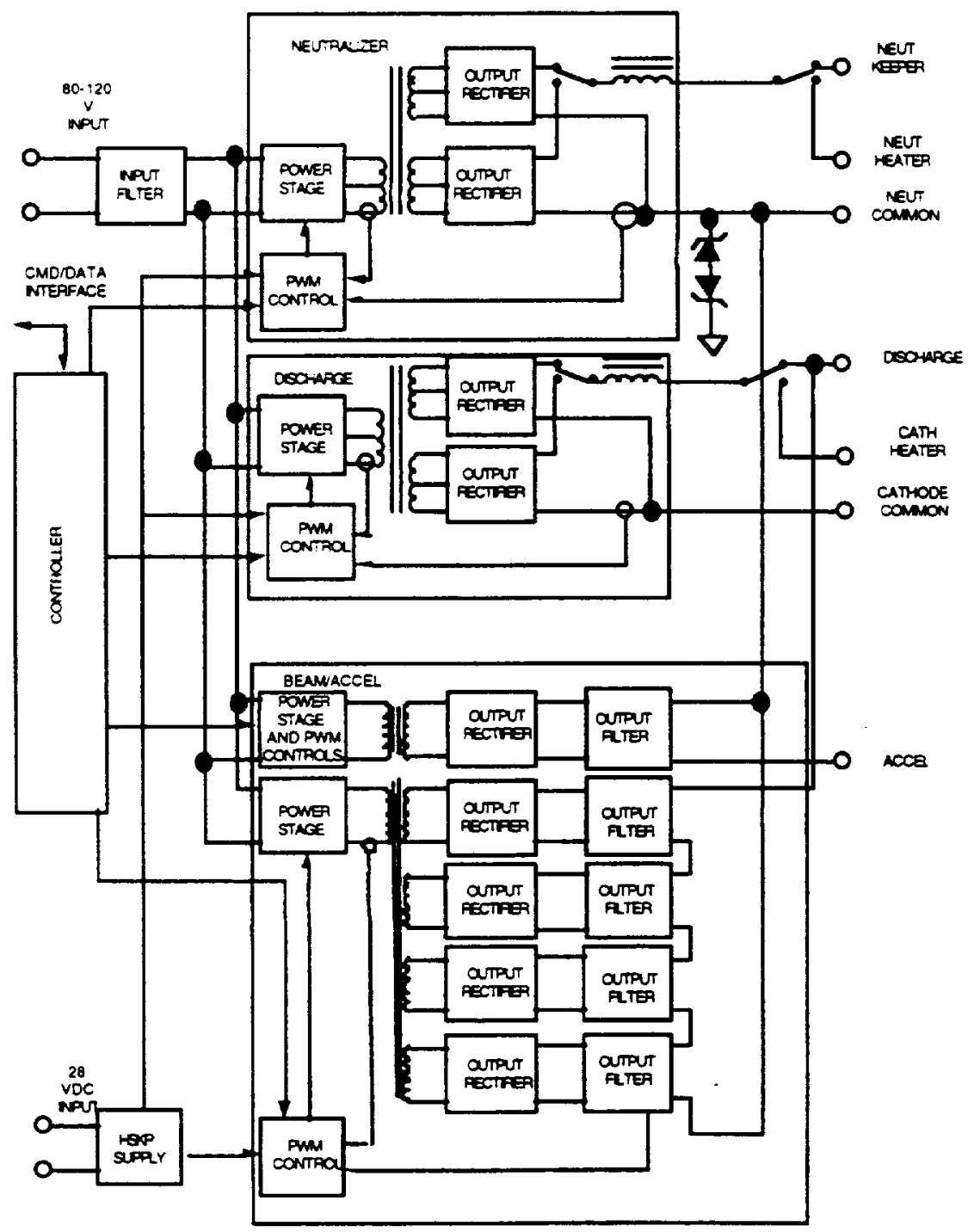

Figure 6. -NSTAR Breadboard Power Processor Block Diagram.

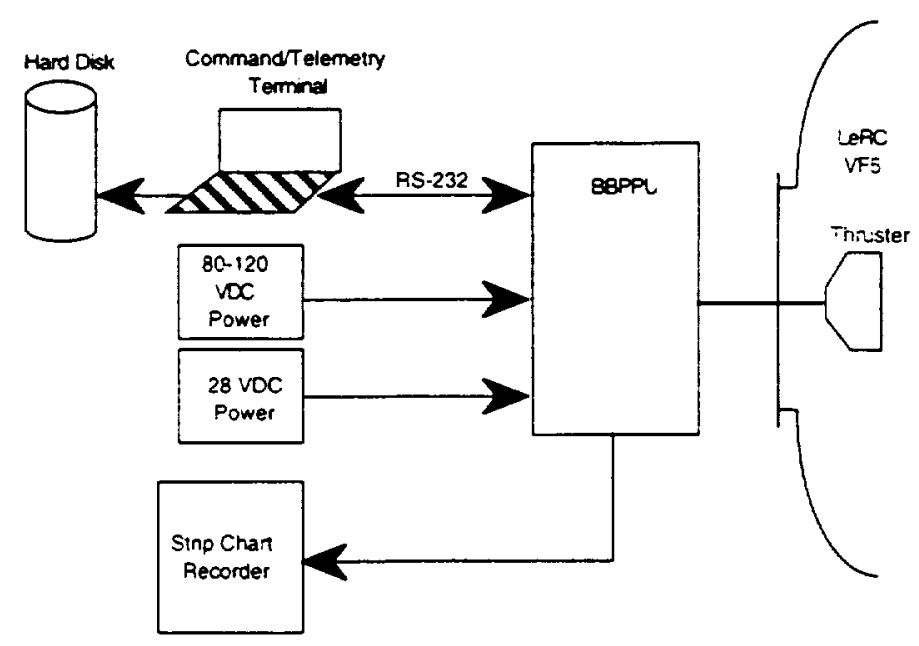

Figure 7.-Functional Integration Test setup for BBPPU and the EMT. 


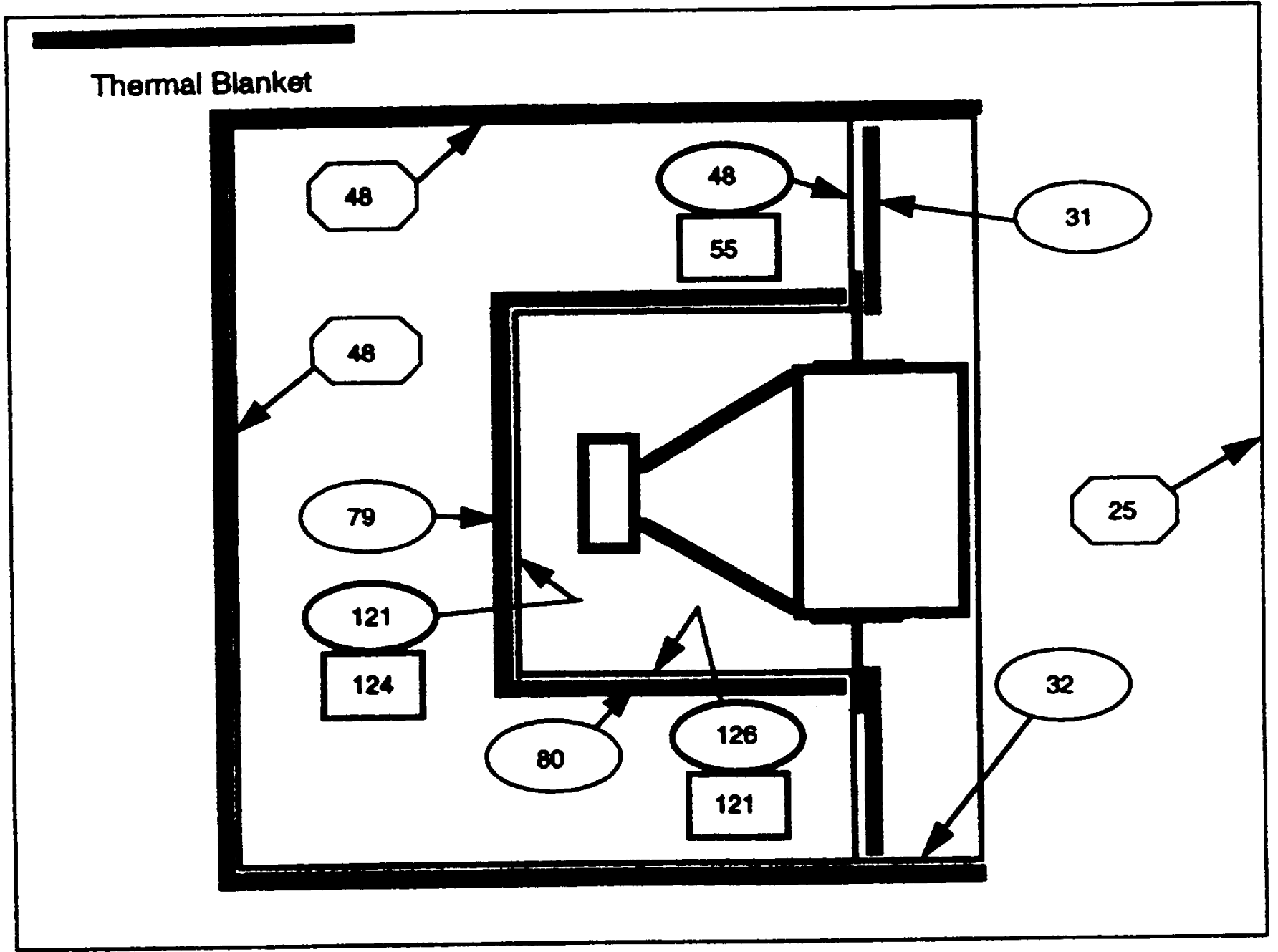

(1) All temperatures in "C.

(2) Test data in rectangles.

(3) Model data in ellipses.

(4) Boundary data in octagons.

Figure 8.-Thruster themal vacuum test setup simulating the DS1 spacecraft configuration. 


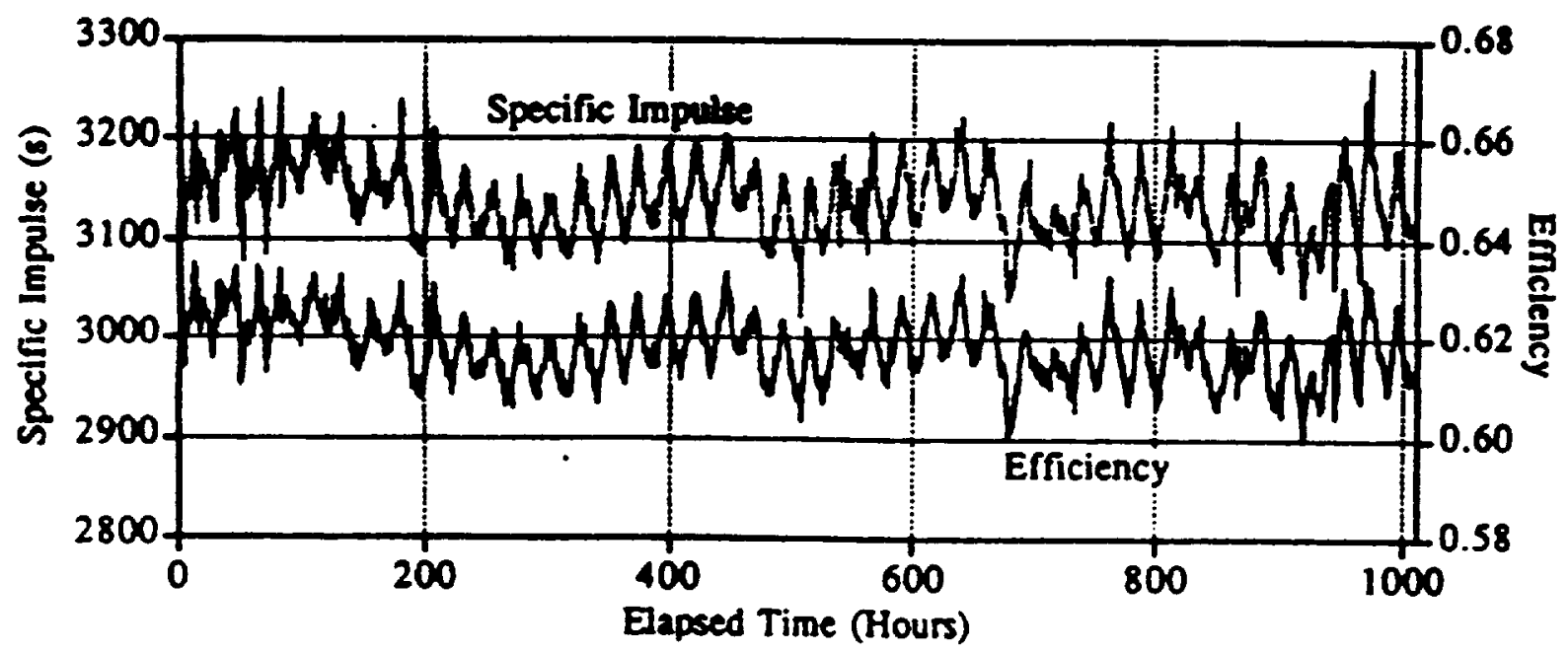

Figure 9.-EMT1b performance versus test time in the $1000 \mathrm{hr}$ test (Ref.10). 


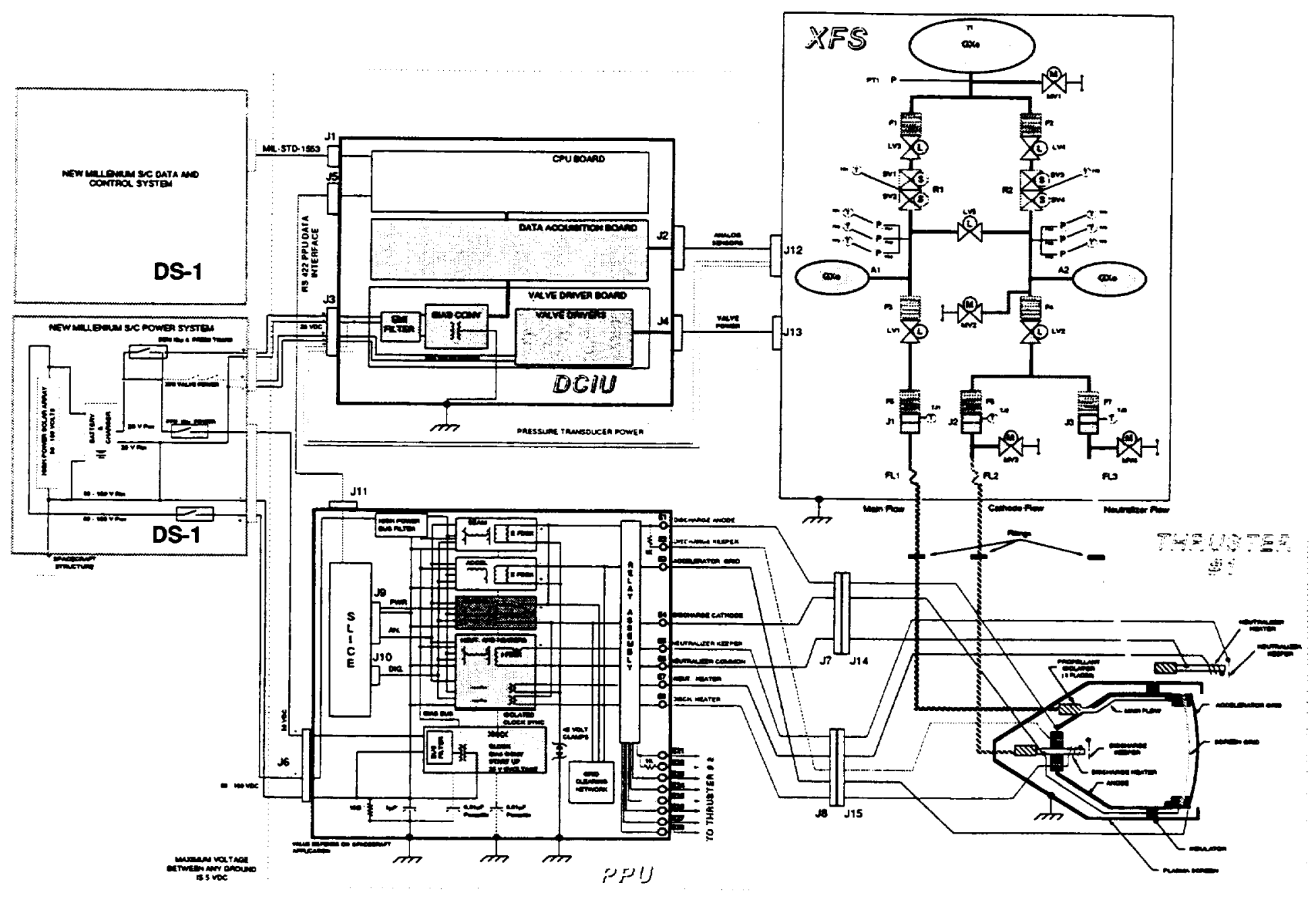

Figure 10.-NSTAR Thruster Element block diagram. 


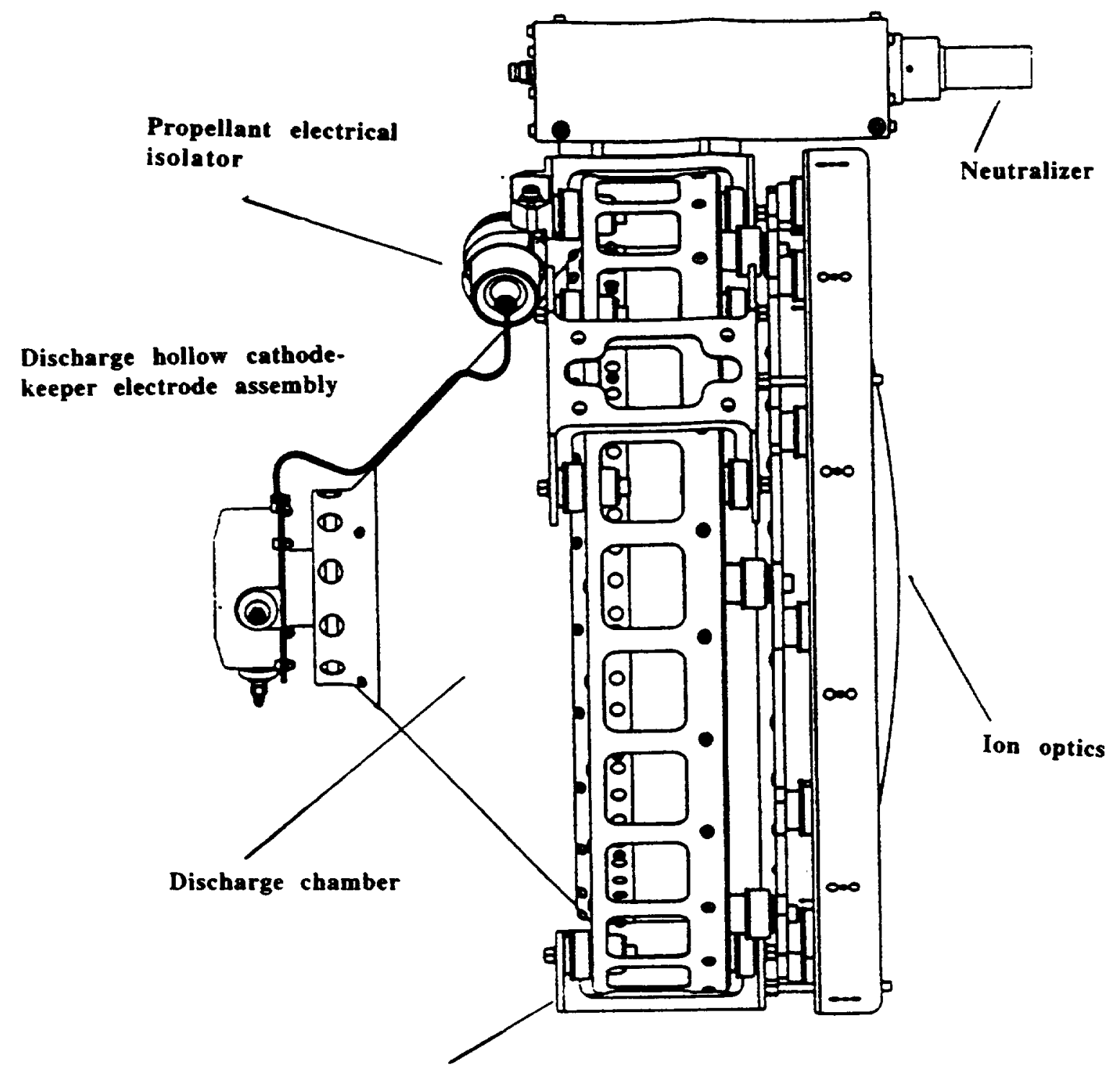

Gimbal bracket

Figure 11.-Graphic of the NSTAR ion thruster without the plasma screen. 


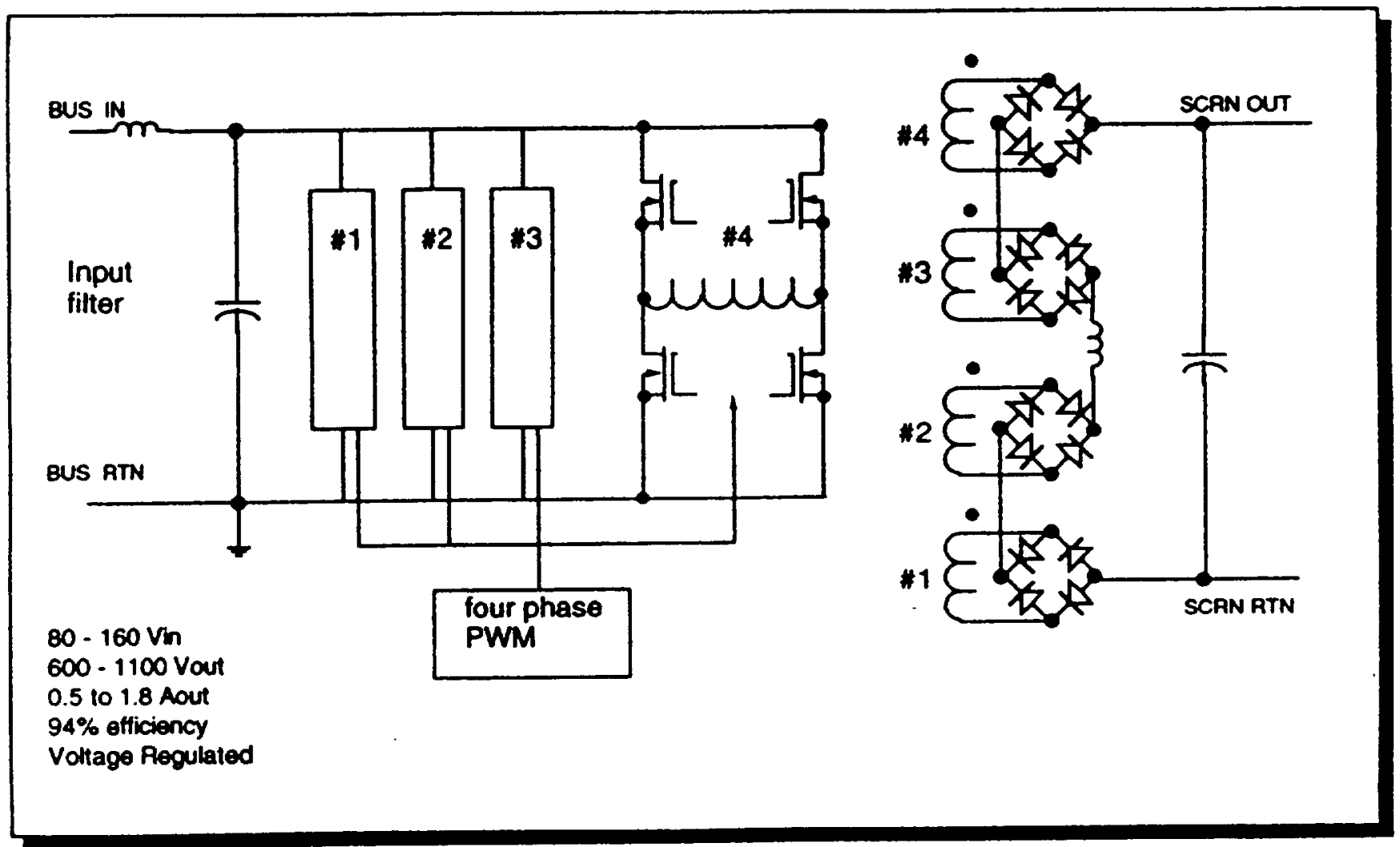

Figure 12.-Beam power supply electrical schematic.

$80 \cdot 160 \mathrm{Vm}$

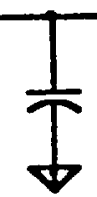

5 - 35 Vout

4 to 14 Aout

$92 \%$ efficiency

Current Aegulated

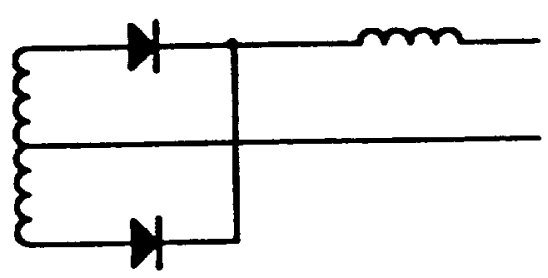

Full bridge PWM with arc starter on eccondary Inductor

Figure 13.-Discharge power supply electrical schematic. 
$80-160 \mathrm{Vin}$

$15-35$ Vout

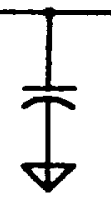

41014 Aout

Neut is Current Regulated

Hir and Accol are Voltege

Regulated

Figure 14.-Electrical schematic of the neutralizer, heaters, and accelerator power supplies. 


\section{REPORT DOCUMENTATION PAGE}

Public reporting burden for this collection of information is estimated to average i hour per response, including the time for reviewing instructions, searching existing data sources, gathering and maintaining the dala needed, and completing and reviewing the collection of intormation. Send comments regarding this burden estimate or any other aspect of this Davis Highway, Suite 1204, Arlington, VA 22202-4302, and to the Office of Management and Budget, Paperwork Reduction Project (0704-0188), Washington, DC 20503.

\begin{tabular}{|l|c|r|}
\hline 1. AGENCY USE ONLY (Leave blank) & $\begin{array}{c}\text { 2. REPORT DATE } \\
\text { December } 1997\end{array}$ & $\begin{array}{r}\text { 3. REPORT TYPE AND DATES COVERED } \\
\text { Technical Memorandum }\end{array}$ \\
\hline
\end{tabular}

4. TITLE AND SUBTITLE

Development of an Ion Thruster and Power Processor for New Millennium's

Deep Space 1 Mission

6. $\operatorname{AUTHOR}(S)$

J.S. Sovey, J.A. Hamley, T.W. Haag, M.J. Patterson, E.J. Pencil, T.T. Peterson, L.R. Pinero,

J.L. Power, V.K. Rawlin, C.J. Sarmiento, J.R. Anderson, R.A. Becker, J.R. Brophy, J.E.

Polk, G. Benson, T.A. Bond, G.I. Cardwell, J.A. Christensen, K.J. Freick, D.J. Hamel, S.L.

Hart, J. McDowell, K.A. Norenberg, T.K. Phelps, E. Solis, H. Yost, and M. Matranga

7. PERFORMING ORGANIZATION NAME(S) AND ADDRESS(ES)

National Aeronautics and Space Administration

Lewis Research Center

Cleveland, Ohio 44135-3191

9. SPONSORING/MONITORING AGENCY NAME(S) AND ADDRESS(ES)

National Aeronautics and Space Administration

Washington, DC 20546-0001
5. FUNDING NUMBERS

WU $-242-70-01-00$

8. PERFORMING ORGANIZATION REPORT NUMBER

$\mathrm{E}-10899$

\section{SUPPLEMENTARY NOTES}

Prepared for the 33rd Joint Propulsion Conference and Exhibit cosponsored by the AIAA, ASME, SAE, and ASEE, Seattle, Washington, July 6-9, 1997. James S. Sovey, John A. Hamley, Thomas W. Haag, Michael J. Patterson, Eric J. Pencil, Todd T. Peterson, Luis R. Pinero, John L. Power, Vincent K. Rawlin, and Charles J. Sarmiento, NASA Lewis Research Center; John R. Anderson, Raymond A. Becker, John R. Brophy, and James E. Polk, Jet Propulsion Laboratory, Pasadena, California 91 109; Gerald Benson, Thomas A. Bond, G. I. Cardwell, Jon A. Christensen, Kenneth J. Freick, David J. Hamel, Stephen L. Hart, John McDowell, Kirk A. Norenberg, T. Keith Phelps, Ezequiel Solis, and Harold Yost, Hughes Electron Dynamics DivisionTorrance, California 90509; Michael Matranga, Spectrum Astro Incorporated Gilbert, Arizona 85233. Responsible person, James S. Sovey, organization code 5430, (216) 977-7454.

12a. DISTRIBUTIONAVAILABILITY STATEMENT

Unclassified - Unlimited

Subject Category 20

\section{2b. DISTRIBUTION CODE}

This publication is available from the NASA Center for AeroSpace Information. (301) 621-0390.

\section{ABSTRACT (Maximum 200 words)}

The NASA Solar Electric Propulsion Technology Applications Readiness Program (NSTAR) will provide a single-string primary propulsion system to NASA's New Millennium Deep Space 1 Mission which will perform comet and asteroid flybys in the years 1999 and 2000. The propulsion system includes a 30-cm diameter ion thruster, a xenon feed system, a power processing unit, and a digital control and interface unit. A total of four engineering model ion thrusters, three breadboard power processors, and a controller have been built, integrated, and tested. An extensive set of development tests has been completed along with thruster design verification tests of $2000 \mathrm{~h}$ and $1000 \mathrm{~h}$. An $8000 \mathrm{~h} \mathrm{Life}$ Demonstration Test is ongoing and has successfully demonstrated more than $6000 \mathrm{~h}$ of operation. In situ measurements of accelerator grid wear are consistent with grid lifetimes well in excess of the $12,000 \mathrm{~h}$ qualification test requirement. Flight hardware is now being assembled in preparation for integration, functional, and acceptance tests.

14. SUBJECT TERMS

Electric propulsion; Ion propulsion; Plasma applications

17. SECURITY CLASSIFICATION OF REPORT

Unclassified
18. SECURITY CLASSIFICATION OF THIS PAGE Unclassified
19. SECURITY CLASSIFICATION OF ABSTRACT Unclassified 
